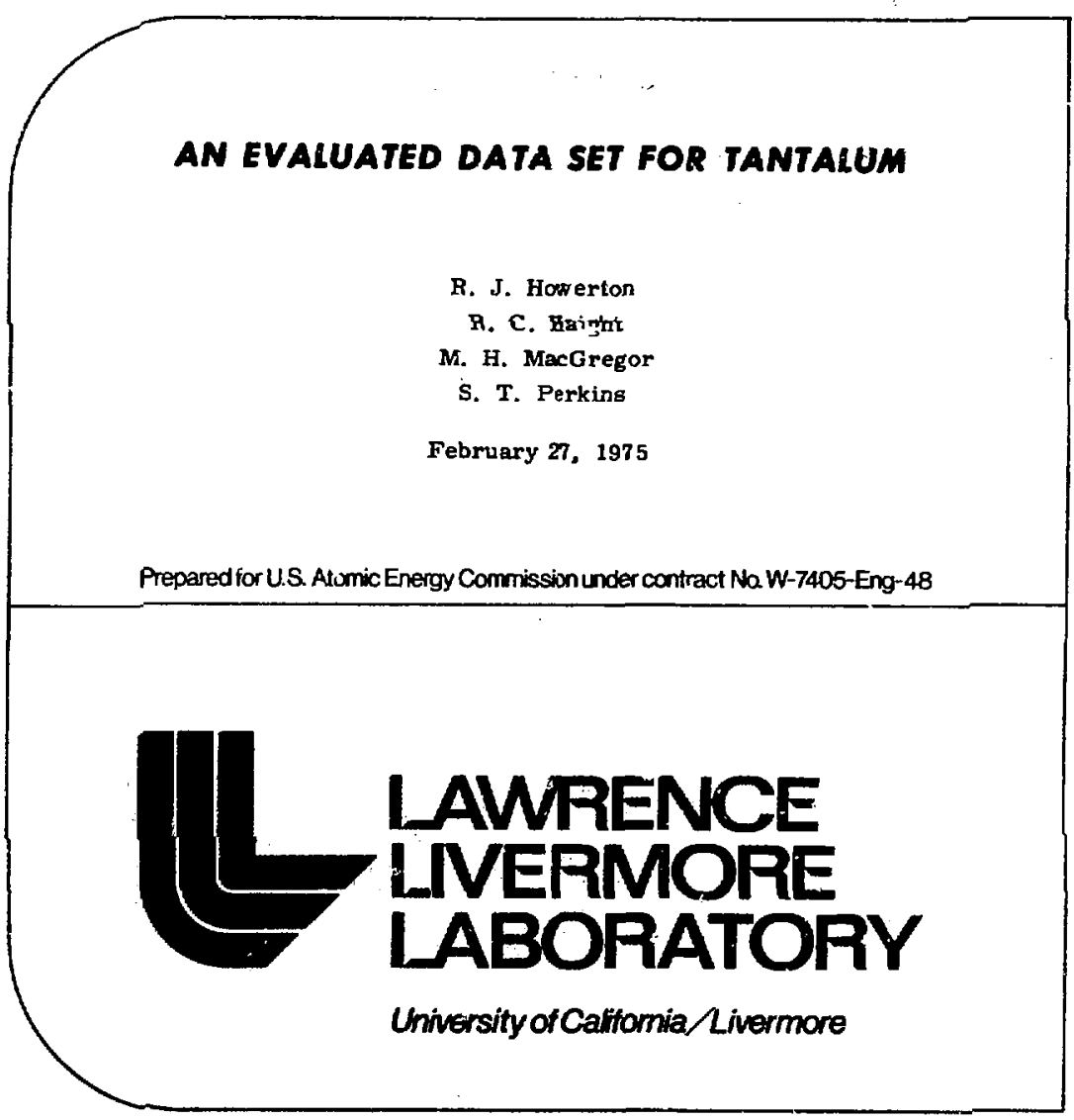




\section{NOTICE}

"This $[$ ". 'n was prepared as an account of work sponsored by the United States Government. Naither the United States nor the United States Energy Rerearch \& Development Administration, nor any of their employees, nor any oi' thetr contractors, subeuntractort, or thejr employees, makes any u'artanty, expregs or implied, or assumes any legal liability or responsibility for the accuracy. completeness or usefulress of any information, sppiratus, product or process disclosed, of represents that its use would not infringe privately=owned rights."

Printed in the United States of America Available from

National Technical Information Service U.S. Department of Commerce 5285 Port Royal Road Springfield, Virginia 22151

Price: Printed Copy $\$$ \& Microf 1 che $\$ 2.25$

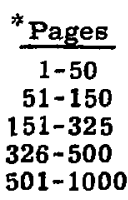

NTIS

Selling Price

$\$ 4,00$

$\$ 5,45$

$\$ 7,60$

$\$ 10,60$

$\$ 13,60$ 
TID-4500, UC- 34

Physics

\section{노}

\section{LAWREACE LNEFMOFE LABORATORY}

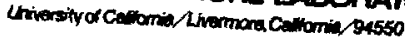

\section{UCRL-51306, Rev, 1 \\ AN EVALUATED DATA SET FOR TANTALUM}

R. J. Howerton

R. C. Haight

M. H. MacGregor

S. T. Perkins

MS, dat ?: February 27, 1975

This repan was NoTiCE

sponsored by the poepared as an wccount of work

the laniled Sthe United Stain Governmenl. Neither

Research and Lever not the United Siats. Energ

their emptoyet not adminisiation, not any of

subconinfines. noz iny' of their contractoss,

wabcontrinctors. of their conployes. mokes any

warraty. expres of implind, or asumes any kgal

liablity at regponsibility for the ficrurscy. completeness

of usefulics of any information, apparafus, product of

infringe pritalely onnof rights that its use would nat 


\section{Contents}

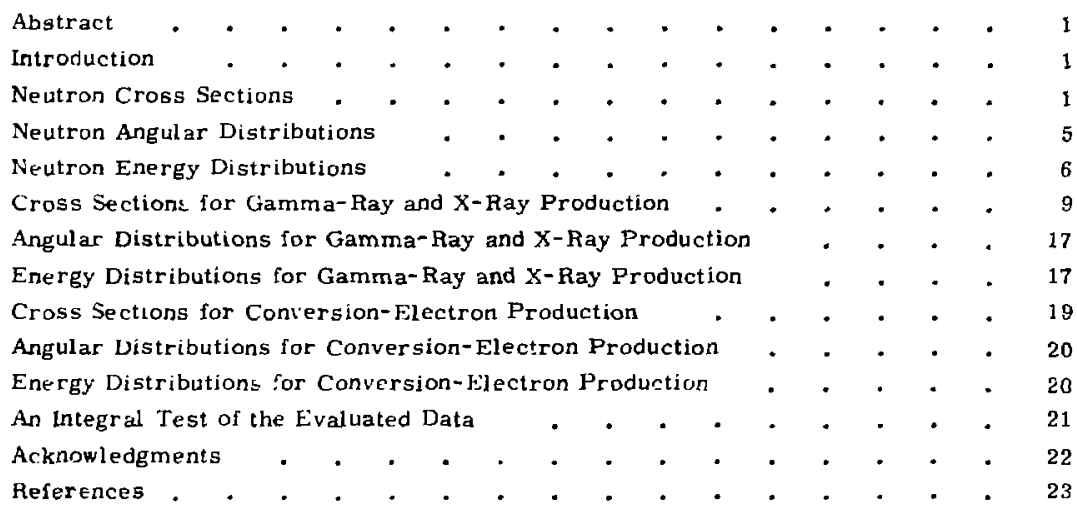




\title{
AN EVALUATED DATA SET FOR TANTALUM
}

\begin{abstract}
The methods used to obtain cross sections and angular and energy distributions for neutron-induced reactions

and gamma-ray, $x$-ray, and conversionelectron production are described for ${ }^{181} \mathrm{Ta}$.
\end{abstract}

\section{Introduction}

This refort describes the derivation of evaluatar neutron-interaction, photonproduction and conversion-electronproduction data for tantalum. It includes bibliographic references to the original experiments upon which the evaluated data are based.

Since natural tantalum is $99.99 \% 181_{\mathrm{Ta}}$, it makes no practical difference whether nalural tantalum or ${ }^{181} \mathrm{Ta}$ is quoted as the source material in experiments. The evaluated data set covers neutron reactions from $0.00001 \mathrm{eV}$ to $20 \mathrm{MeV}$. In this energy range, in addition to elastic scattering, a number of nonelastic reactions are energetically possible. Table 1 lists the se reactions, their thresholds, and references that give the threshold energies.

Of the reactions that produce charged particlee, all bot the $(n, p)$ reaction have been ignored, as there are essentially no measurements for the $m$ and their cross sections are estimated to be negligible. The nonelastic reactions that are included in our evaluated data set are $(n, n),(n, 2 n)$, $(n, 3 n),(n, p)$, and $(n, \gamma)$.

Table I. Nonelastic neutron reactions.

\begin{tabular}{|c|c|c|}
\hline Reaction & $\begin{array}{c}\text { Threshold } \\
\text { (MeV) }\end{array}$ & $\begin{array}{c}\text { Ref- } \\
\text { erences }\end{array}$ \\
\hline$n, n^{\prime}$ & 0.00623 & 1 \\
\hline$n, 2 n$ & 7.69 & 2 \\
\hline$n, 3 n$ & 14.3 & 2 \\
\hline$n, p$ & 0.24 & 2 \\
\hline$n, n p$ & 5,97 & 2 \\
\hline$n, d$ & 3.73 & 2 \\
\hline$n$, nd & 11.16 & 2 \\
\hline$n, t$ & 4.87 & 2 \\
\hline$n, n t$ & 11.00 & 2 \\
\hline $\mathrm{n}, \mathrm{He}_{3}$ & 6.20 & 2 \\
\hline$n_{1} \mathrm{nHe}_{3}$ & 13.24 & 2 \\
\hline$n, \alpha$ & Exoergic $\{Q=7,41\}$ & 2 \\
\hline$n, n \alpha$ & Exoergic $\{Q=1.53\}$ & 2 \\
\hline n, $\gamma$ & Exoergic $\{Q=6.06\}$ & 2 \\
\hline
\end{tabular}

\section{Neutron Cross Sections}

\section{TOTAL CROSS SECTION}

In the neutron enery region below $300 \mathrm{EV}$, the total cross section consists of elastic scattering plus neutron capture, as expressed in a set of resolved resonance parameters. For this part of the evaluated data set, we have useda standard 
set of resolved resonance parameters [BNL-325, Suppl. 2, Vol. IIc, (1966)] ts generate the cross sections. In the erergy region fro.n $300 \mathrm{eV}$ to $20 \mathrm{MeV}$, tot: cross sections were taken from the experimental data of Refs. 3 through 19. Total cross sections have been measured over this energy range to quoted accuracies of about $2 \%$. However, the scatter in data among different experiments a mounts to about $10 \%$ over the entire energy range. Hence the evaluated total cross sections have an estimated error oi about $5 \pi$.

\section{NONELASTIC CROSS SECTION}

Measurements of the nonelastic cross section have been made at $1 \mathrm{MeV}, 20$ $2.5 \mathrm{MeV},{ }^{21} 4.1 \mathrm{MeV}^{9} 7 \mathrm{MeV}^{21}$ and $14 \mathrm{MeV}^{22}$ The noneiastic cross sections entered into the present evaluation are in agreement with the measured values. At It Mel, the evaluated nonelastic cross section lies at the upper edge of the relatively large error band for the experimental value. ${ }^{22}$ which was obtained from an early emulsion experiment. The choice made for the nonelastic cross section at $14 \mathrm{MeV}$ is in reasonable agreement with systematics. Experimental determinations of the nonelastic cross section have quoted uncertainties of $\pm 10 \%$ in tile 2.5 to $7-\mathrm{MeV}$ range and $\pm 20 \%$ at higher and lower energies. When information from systernatics is included, the evaluated nonelastic cross sections are probably accurate to $\pm 10 \%$.

\section{ELASTIC CROSS SECTION}

Below $300 \mathrm{eV}$, elastic crosa sections were obtained for the evaluated data set by using the resolved resonance parameters listed in BNL-325, Suppl. 2, Vol. Llc (1966). This resonance parameter set is based on a single-level analysis with an assumed material temperature of $0^{\circ} \mathrm{K}$. The elastic cross section is equal to $6.25 \mathrm{~b}$ at $0.0253 \mathrm{eV}$ and is essentially constant over the region of thermal and subthermal $\in$ nergies. Above $300 \mathrm{eV}$, the elastic cross section was set equal to the difference between the evaluated total and nonelastic cross sections, which were obrained from measurements as described above.

Direct measurements of the elastic cross section have been made at some energies, $20,23-26$ These measured values are in general agreement with the values obtained by taking the differences between total and nonelastic cross sections. Since evaluated total and nonelastic cross sections have respective errors of $\pm 5 \%$ and $\pm 10 \%$, the evaluated elastic cross sections have accuracies of about $\pm 10 \%$.

\section{NONELASTIC REACTION CROSS} SECTIONS

Vonel astic reaction cross sections incluce th: $\left(n, n^{\prime}\right),(n, 2 n),(n, 3 n),(n, p)$, and $(n, r)$ reactions.

$\underline{\langle n, n} \underline{\text { Reaction }}$

Intelastic excitation cross sections in tant:lum have been medsured to six differe it groups of levels. ${ }^{24}$ The lowest three groups are probably doublets, the next two are probabiy triplets, and the highest may be a single level. 1 To resolve the doublets, the recent $\left(n, n^{\prime} \gamma\right.$ ) gamma ray data of Dickens and Morgan 27 were used. The normalization of Ref. 24 was preferred, and a compromise was 
made between the excitation functions of Refs, 24 and 27. The levels at 0.1361 , $0.1586,0.3015,0.3375,0.4822,0.495$, $0.620,0.720$, and $0.925 \mathrm{MeV}$ are included in this evaluation.

Reference 24 diu not include data for the lowest - lying level at $0.00623 \mathrm{MeV}$, because the inelastic neutrons from that level are experimentally unresolvable from elastic neutrons. Whether the level is includeo at all in the evaluation is of little importance from the point of view of neutron transport, and it is therefore neglected as a discrete 'evel excitation in the $(a, n)$ reaction. 1 is, however, of some importance in terms of conversionelectron production. We have used calculated values obtained by Donald Gardner with the COMNLC code 28 for this latter pispoose.

Continuum inelastic-scattering cross sections were abtained by differencing the total nonelastic cross section and the sum of the partial nonelastic cross sections after the nonelastic cross section and all other jonelastic reactions have been evaluated. In addition to the data of Smith, ${ }^{24}$ other references to $\left(n, n^{\prime}\right)$ scattering are given in Refs. 23 through 35. The evaluated cross sections for excitation to specific levels are accurate to $\$ 20 \%$, whereas the continuum $\left(n, n^{\prime} \gamma\right)$ cross section is estimated to be accurate to about $\pm 40 \%$.

\section{(n,2n) Reaction}

There have been a number of measurements of this crose section. $22,35-41$ How ever, most of them were activation measurements based on the $8.1-\mathrm{h}$ isomer. $36-41$ Since production of this isomer represents lese than half of the total $(n, 2 n)$ cross section, these measurenents are not very helpful in determining the total $(n, 2 n)$ cross section. The only ather data are 14-MeV measurements ${ }^{22}$ so they give no information as to the shape of the $i n, 2 n$ ) cross section.

Furtheimore, Ref, 22 is an early plate experiment. Reference 35, a large scintillator experiment in which one of us (M, H, M.) participated, gives a value for the (n, 2r) cross section that is larger than the nonelastic cross section. Fortuitously, taking an average of Refs. 19 and 35 gives an $(n, 2 n)$ cross section at $14 \mathrm{MeV}$ $(2.2 \mathrm{~b})$ that is in reasonable agreement with the systematics of other reactions in tantalum. But we still have to determine the shape of the $(n, 2 n)$ excitation function over the remainder of the energy range f:orr threshold to $20 \mathrm{MeV}$.

In the first pass at pioducing a tantalum evaluation, we assumed an $(n, 2 n)$ cross secticn that rose rather slowly from the 7.69-MeV threshold value. However, recert data ${ }^{42}$ v. .1 combined with theory, showed that this slow rise in the ( $n, 2 n)$ cross section is probably not correct. These new data were combined with theory and incorporated into tne evaluation in the following manner.

Howerton and Plechaty ${ }^{43}$ in 1968 provided a formalism for calculating gammaray production cross sections and energy distributions. This formalism implies that the production of gamma rays will fall off sharply just above the $(n, \angle n)$ threshold because the emission of a second neutron will compete strongly with the emission of gamma rays. The validity of this implication was strikingly confirmed in a recent measurement of gammaray production from neutron bombardment 
oi tantalum made by an Oak Ridge group. ${ }^{42}$ As predicted by Howerton and Plechaty, the gamma-ray production curve (Fig. 18 of Ref. 42) shows a sharp drop for neutron energies immediately above $8 \mathrm{MeV}$. Furthernore land in line with present purposes), the magnitude of the drop in the gamma-ray production dat a can be used to deduce how fast the $(n, 2 n)$ cross section must be rising. The Oak Ridge data shows rather clearly that the slow (first-pass) rise for the (n, 2n) cross section could not be correct.

In examining other heavy elements to see what the shape of the $(n, 2 n)$ cross section looks like near threshold, we found that the only element for which a good $(n, 2 n)$ shape has been measured is ${ }^{238} \mathrm{~L}$. Thus, as a means of improving the evaluation of the shape of the $(n, 2 n)$ cross section, we used the measured shape for ${ }^{238} \mathrm{U}$, adjusting the abscissa to allow for the difference in threshold energies. The ordinate was changed to match the 14-MeV cross section value of 2.2 b. When this modified $(n, 2 n)$ cross section was used in a calculation and compared with the Oak Ridge gamma-ray data, good agreement was obtained.

The gamma-ray calculation is summarized in the section on gamma-ray production. The modified $\{n, 2 n\}$ data was inferted into the final tantalum evaluated data set. When the various systematic constraints on the $(n, 2 n)$ cross section are taken into account, the $(n, 2 n)$ evaluated cross sections are probably accurate to $115 \%$ in the neighborhood of $14 \mathrm{MeV}$, although the errors strely exceed this amount in steeply rissing regions near threshold and at high energies (15 to $20 \mathrm{MeV}$ ).

\section{$\{n, 3 n\}$ Reaction}

No measurement of the $(n, 3 n)$ reaction has been made for tantalum. The $(n, 3 n)$ cross section was deduced from systematics, with (hopefully) judicious adjustment of the $(n, 2 n)$ and $\left(n, n^{\prime} \gamma\right)$ cross sections to maintain the estimated nonelastic cross section. The uncertainties in the evaluated cross sections are estimated to be 60 to $80^{\%}$, since the differences of poorly determined quantities are involved.

\section{(n, p) Reaction}

The $(n, p)$ cross section is several orders of magnitude smaller than the cross sections discussed above. Two measurements of tantalum $(n, p)$ cross sections exist, spanning the energy range from 13 to $17.5 \mathrm{MeV} .{ }^{44,45}$ Reference 45 was used together with an extrapolation of the cross section down to the threshold energy of $0.24 \mathrm{MeV}$ as the basis for the evaluation. The evaluated ( $n, p)$ data are estimated to be accurate to $\pm 90 \%$, which is prcbably adequate considering the smallness of the cross sections.

\section{(n, $\gamma)$ Reaction}

Many measurements have been made of the $(n, y)$ cross section. ${ }^{45-71}$ The energy range for these measurements extends from thermal energies to $5 \mathrm{MeV}$. In the energy region below $300 \mathrm{eV}$, the resolved resonance-parameter set mentioned atove [BNL-325, Suppl. 2, Vol. Ilc, (1966) was used to obtain the neutroncapture cross section. From $300 \mathrm{eV}$ to $5 \mathrm{MeV}$, the $(\mathrm{n}, \gamma)$ cross se, 1 ion was determined from the measured $d d a$. Above $5 \mathrm{MeV}$, the $(n, \gamma)$ cross section is very small, and any ruasonable extrapolation procedure gives adequate values for it. 
In the resolved resonance region, the errors are about $\pm 20^{\circ}$. In the unresolved resonance region and above, the errors are about $\pm 25 \%$.

\section{Neutron An sular Distributions}

ANGLLAR DISTRIBLTIONS FOR ELASTIC SCATTERING

Experimental measurements of the angular distribution for elastic scattering of n-utrons from tantalum have been made at a series of energies ranging from 0.06 to $14.6 \mathrm{MeV} .9,20-22,24,26,30,72-82$ At neutron energies below $0.05 \mathrm{MeV}$, the elastic scattering was assumed to be isotropic in the center-of-mass system. Between 0.05 $\mathrm{MeV}$ and I.0 MeV. the elastic angular distributions were taken from experiment. Cpticai-model calculations were done for incident neutron energies between 1.0 and $20 \mathrm{MeV}$.

For all energies in this range $w$ here experiments had been done, the agreement between calculation and experiment for angles less than $30^{\circ}$ was very good. The locations of maxima and minima were accurate, as were the magnitudes of the relative maxima As would be expected, tise calculated minima showed strong disagreements with the experimental minima, since the experimental resolution could not eliminate either the direct level txcitation for low-lying levels or the high-energy preequilibrium component of inelastic scattering. This apparent disagreement in the minima was resolved by using the optical-model results for the evaluation.

The optical-model results agree well with experiment in the region where most of the cross section lies. We knew of no other way of correcting satisfactorily for the experimental resolution problem in the region of the minima. Elasticscattering angular distributions have average data-point uncertainties of about $\pm 15 \%$ in addition to the normalization uncercainty of $\pm 10 \%$ for the total elasti: cross section.

ANGULAR DISTRIBUTIONS FOR NONELASTIC SCATTERING

The fe $w$ available experimental $\operatorname{dat} a^{24,26}$ indicate that angular distributions of the neutrons scattered from specific levels are essentially isotrofic in the cente- of-mass system. Hence isotropic center-of-mass angular distributions wert uscd to determine the $\left(n, n^{\dagger} \gamma\right)$ excitations to specific lovels. The $(n, 2 n)$ and $(n, 3 n)$ processes were assumed to be isotropic in the laboratory frame of reference. Experimentally. 83 this approximation appears to be justified.

Eor incident neutron energies below $7 \mathrm{MeV}$, the continuum $\left(n, a^{\prime} \gamma\right)$ neutron. were assumed to be isotropic in the $1 a b-$ oratory frame of reference. For incident neutron energies greater than $7 \mathrm{MeV}$, anisotropic angular distributions were assumed, since the neutrons from the ( $n, n^{\prime} \gamma$ ) reaction at incident neutron energies greater than 7 Me $\mathrm{r}$ show a distinct forward peaking of the nonequilibrium neutrons. Insufficien experimental data exist to provide for the energy-angular correlation of these neutrons, and a correlation cannot be obtained as with a 
unique two-body breakup reaction, so an estimated average anisotropy was used.

'The errors in the angular distributions for discrete-level scattering and for $(n, 2 n)$ and $(n, 3 n)$ processes are estimated to be about 10 to $15^{\prime \prime}$. The errors in the high-energy $\left(n, n^{\prime} \gamma\right)$ contirutum angular distributions may be as much as a factor of 3 for some neutrons at some angles.

\section{Neutron Energy Distributions}

The formalism that we used to specify the nonelastic neutron spectra is described individually for each of these reactions. Although much of the following discussion is couched in terms of the evaporation model, the energy distributions are presenteci exclusively as tables. Since not all distributions can be represented in the evaporation formalism, but all can be represented by tahles, a tabular representation preserves consistency. $A$ minor but pertinent point is the choice of the low-energy cut-off if nuclear temperatures are presented. The tables nake the intended use of the data explicit.

(n, n') REACTION

The energy diagram for continuum $\left(n, n^{\prime}\right)$ reactions is shown in Fig. 1. T'No energy ranges can be defined:

$$
E_{n}=E_{n}^{L}<7.7 \mathrm{MeV}
$$

and

$$
\mathrm{l}_{\mathrm{n}}=\mathrm{E}_{\mathrm{n}}^{\mathrm{H}}>7.7 \mathrm{MeV}
$$

wherc $E_{n}$ is the incident neutron energy and $7.7 \mathrm{MeV}$ is the $(n, 2 n)$ threshold. In the $E_{n}^{L}$ energy region, only $\left(n, n^{\prime}\right)$ reactions are possible (if $n, p$ and $n, \gamma$ reactions are neglected), and the $\left(n, n^{n}\right)$ neutrons forn a typical boilofr spectrum.

Reference 30 gives boiloff temperatures for incident neutron energies between 2.44 and $7 \mathrm{MeV}$. In general, the temperc.ture will scale ${ }^{84}$ as $U_{A}^{1 / 2}$, where $U_{A}$ is the excitation energy shown in Fig. 1. This temperature is a property cf the final-state nucleus, since it characterizes the density of final states available for the inelastic neutron emission. If the maitix elements for decays to these final states are roughly constant, then the decay probabilities, and hence the tempel ature of the neutron spectrum, will be proportional to the density of finai $E$. Les.

In cases where thr temperature is determined by interpolation or extrapoliation, an iterative calculational scheme was used: an average neutron secondary energy was estimated, and the corresponding final-state temperature from the $\mathrm{U}_{\mathrm{A}}$ value and the aver $\mathrm{b}^{\circ}$ neutron energy corresponding to this temperature

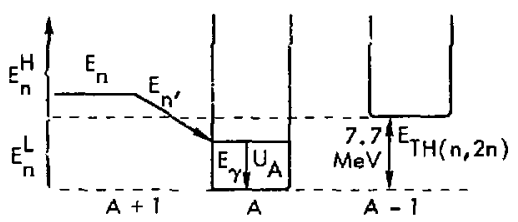

Fig. 1. Available-energy diagram for the $(n, n$ ') reaction. 
werc calcuiated. Il this avcrage neutron energy was diffurt irom the original estimate, an iteration was carried out to bring these quantities into agreernent. In the $\mathrm{E}_{n}^{\mathrm{H}}$ incident neutron-energy range, we assumed that for $\mathrm{E}_{n} \geq 7.7 \mathrm{MeV}_{\text {. }}$ the inclastic neutron onergy $F_{n}^{\prime}$ (see Fig. 1) $u$ ill be large enough to leave the residual (A) nuclews below the $(n, 2 n)$ threshoid; otherwise, the emission of a second neutron was assumed to occur. Thus, for $E_{n} \geq 7 . ; M e V$, the $E_{n}^{\prime}$ neutrons from the $\left(n, n^{\prime}\right.$; reaction are all highenergy neutro's, with energies ranging from $E_{n}$ down to $E_{n}-7.7 \mathrm{MeV}$. The spectral shape for these high-energy inelastic neutrons has been measured at $14 \mathrm{MeV}^{85}$ and the same shape is assumed tu apply at $20 \mathrm{MeV}$. At $7 \mathrm{MeV}$, the inelas.ic spectrum is the boiloff spectrum described above for the $\mathrm{E}_{\mathrm{n}}^{\mathrm{L}}$ region. At incident energies of 9 and $11 \mathrm{MeV}$, the (n, n') spectrum is taken to be intermediate between the 7 - and 14-MeV spectra. In additior to the $\left(n, n^{\prime}\right) \mathrm{E}_{\mathrm{n}}^{\mathrm{L}}$ and $\mathrm{E}_{\mathrm{n}}^{\mathrm{H}} \mathrm{in-}$ elastic neutrons from the $\left(n, n^{i}\right)$ continuum, there are also $(n, n)$ neutron, from the nine low-lying liscrete levels described in the section on Partial Nonelastic Cross Sections. For these reactions the secondary neutron energies are determined by two-body kinematics, using the assumption of isotropy in the center-of-mass system.

\section{(a, 2n) REACTION}

Figure 2 shows the cascade sequence leading to the $(n, 2 n)$ reaction. The first and second neutrons, $E_{n_{1}}$ and $E_{n_{2}}$, follnu bo:loff spectra characterized by the temFeratires $\mathbf{T}_{1}$ and $T_{2}$ and by the finalstate excitation energies $U_{A}$ and $U_{A-1}$, respectively. In general, experiments measure a combinid n:ut on-energ. spectrim for all nonelasic neutrons. However, the method of Ling and Le Conteur ${ }^{84}$ can be used to unfold this spectrumi and deduce the temperatures $T_{1}$ and $T_{2}$

In tantalum, the $(n, 2 n)$ neutron-energy spectrum has been measured at 14 MeV. $2:, 85,87$ In the present evaluation, values for $T_{1}$ and $T_{2}$ at 14 MeV were taken trom Ref. 31. At other neutron bomtarding energies, the scaling laws $T_{1} \propto U_{A}^{1 / 2}$ and $T_{2} \times U_{A-1}^{1 / 2}$ were used to obtain the $(n, 2 n)$ netution spect:a, As described in the previous scction, an iterative calculation was used to make the assumed average neutron energies $\bar{E}_{n_{1}}$ and $\bar{E}_{n_{2}}$ agree with those calculated from the corresponding temper atures $T_{1}$ and $\mathrm{T}_{2}$.

In carrying out detailed calculations of the $(n, 2 n)$ cascac'e process (Fig. 2), it is necessary to traat the first and second neutrons separately. However, in the final evaluated $(n, 2 n)$ inelastic neutron specirum, this separation of first and second neutrons seems neither necessary nor just tied by our physical knowledge

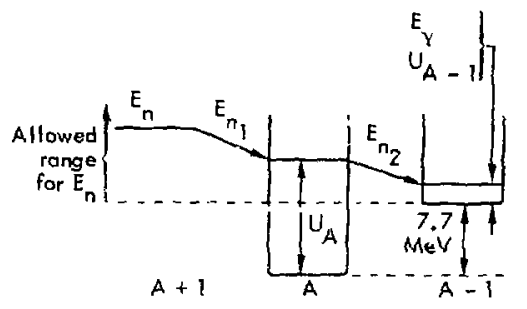

Fig. 2, Avalable-energy diagram for the $(n, 2 n)$ reaction. 
of th situation. Accordingly, in the final eval uated data set the $F_{n_{1}}$ and $E_{n_{2}}$ neutron spectra at each incident energy were combined into a single $(n, 2 n)$ neutron spectrum. We calculated an effective temperature $T$ that gives the correct average neutron energy sor the combined spectrum ronsistent with the upper-limil cutoff on the spectrum (the upper limit is determined by the available energy). In Fig. 2, the residual excitation energy, $\mathrm{U}_{\mathrm{A}-1}$, was assigned to the production of gamma rays.

\section{(a, 3n) REACTION}

The cascade sequence for the (n $3 n$ ) reaction is shown in Fig. 3 . The systematirs for the calculation of this rea:tion are similar to the $(n, 2 n)$ systematics, though no measurements of the average neutron tenperature exist for $(n, 3 i)$ reactions in tantalum. However, if it is assumed that the temperature $T$ of a spucific nueleus is proportional to the square root of the a vailable energy of that nucleus, the constants of proportionality $\mathrm{C}_{1}$ and $\mathrm{C}_{2}\left(\mathrm{~T}_{1}=\mathrm{C}_{\mathrm{i}} \mathrm{U}_{\mathrm{A}}^{1_{1}^{\prime}}\right.$. $\left.T_{2}=C_{2} U_{A-1}^{1 / 2}\right)^{2}$ for the tirst and second neutrons in the $(n, 2 n)$ reaction turn nut to be alinost equal: $c_{1}=0.27$ and $C_{2}$

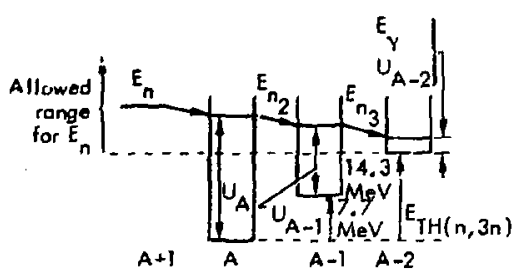

Fig. 3. Avallable-energy diagrarn for the (n, 3n) reaction.
$=0.24$. These constants should auso apply for the first two neutrons in the $\left(n, 3 n\right.$ ) cascade. The constant $C_{3}=0.25$ was as sumed for the third neutron. Although we used the same constants, $C_{1}$ and $C_{2}$, for both $(n, 2 n)$ and $(n, 3 n)$ reactions, it is much harder to calculate the $(n, 2 n)$ than the $(2,3 n)$ spectra. The individual excitations $\tau_{A}$ and $\mathrm{J}_{\mathrm{A}-1}$ for the $(n, 2 n)$ reaction are on the average cousidexably latger than the individial excirations $U_{A}, U_{A-1}$, and $U_{A-2}$ for the $(n, 3 n)$ reaction.

As in the case for $(n, 2 n)$ reactions, the three separate $\left(n_{t} 3 n\right)$ neutron spectra calculated at each incident neutron energy were combined into a single final $(n, 3 n)$ neutron spectrum. An effective temperature was chosen to preserve the correct average energy, using the proper highenergy cutoff on the spectrum. The residual excitation energy, $\mathrm{U}_{\mathrm{A}-Z}$, was assigned to gamma radiation (Fig. 3 ).

in the $\left(n, n^{\prime}\right),(n, 2 n)$, and $(n, 3 n\rangle$ reactions, the available energy that is not taken away by final-state inelastic neutrons was assigned to radiation of photons and cnnversion electrons. Thus, on the average, energy is conserved in the evaluation for combined neutron emission plus other radiative processes.

This overall conservation of energy has a special significance, because recent accurate gamma-ray production data 42 can be used to check the accuracy of the ussociated neutron reactions. Yet, ever with the available cross check provided by the data, the uncertainties in the secondary energy distributions at any specific energy are very large, varying from 20 to $30^{\%}$ at best to noders of magnitude at the worst. Measurements of secondary 
spectra generally have a low-energy cutoff no lower than $500 \mathrm{k} \in \mathrm{V}$. The nuclear temperatures derivod rrom such csperiments are determined only from the intermediate-finergy secondary neutrons, for example from 1.5 to $5 \mathrm{Mel}$, thereby excluding both the high- and low-energy portions of the spectrum.

\section{Cross Sections for Gamma-Ray and X-Ray Production}

Tre first analysis of the ${ }^{181} \mathrm{~T}$ ह (n, $\left.x^{*}\right)$ cross section and photon spectra was mace in 1971 . Hecause of limited experimental data, a good portion of those results were cxtrapolated from tungster. Recently, new experimental data on ${ }^{181} \mathrm{Ta}$ have become available. This $\mathrm{m}$ ! orily has given specific information on the isotope of interest, but also has allowed the technique of analys is to be improved.

The major component of the $(n, x \gamma) r e^{-}$ action in ${ }^{181}$ Ta comes from rontinuam gammas." A revitew of this theory will therefore be presented, along with a discussion of the extensions made to analysis as a result of new data, Comparisons of calculation to experiment will be shown. Finaily, the techniques for ubtaining all components of the evaluated $(n, x y)$ cross section and spectra over the various neutron-energy ranges will be presented.

\section{THE FIRST-PASS $(n, x \gamma)$ EVALUATION}

In 1968, Howerton and Plechaty ${ }^{43}$ published a formal ism for the calculation of $(n, x, \gamma)$ crose sections and spectra above

\footnotetext{
In the following discussion ano in the evaluation, photons resulting from the $(a, p)$ reaction are ignored because of its small cross section, the lack of experimenta) data, and the ab.ence of an adequate theory to estimate the contribution from the $(n, p)$ reaction.
}

4-MeV incident neutron energy. Their technique was based nn the obserration that the experimental spectrum of continuum gammas follows the simple evapporation model. From measured spectra, the $\mathbf{R}$ parameter (similar to the inverse of a nuclear temperature in the usual evaporation model) may be determined as a iunction of incident neutron eneigy. The multiplicity is uniquely defined in terms of the $R$ parameter; hence the $(n, x \gamma)$ cross section may be obtained, and the problem is cornpletely specified.

Because data were only available at 4 and $14 \mathrm{MeV}$, Ref. 43 assumed a linear dependence of $R$ on the incident nectron energy. However, in late 1371, all of the $\left(n, x^{*}\right)$ spectra in the LLL Experimental Neutron Cross-Section Information Library (ECSIL) were analyzed for $R$ parameters. ${ }^{B B}$ From these results, it became apparent that the behavior of the $R$ parameter was not linear over the entire range of neutron energy. In the enexgy region where the $\left(n, n^{\prime} \gamma\right)$ reaction is predominant, the behavior is essentially iinear. However, at higher energies (e. g.: $14 \mathrm{MeV}$ ) the experimental values lie above, and at lower energies [i. e., below the (n, n'r) thresluold) they lif bolow this linear behavior. This may be seen in Fig. 4, where the experimental $R$ parameters for tungsten are given. 
In view of the above, a more reasonable assumption is that tie $H$ parameter is an explicit function of the excitation energy in the residual nucleus, rather than a function of the incident neutr:n energy. The results of this assumption can be illustrated by considering tungsten (Fig. 4). If about $6 \mathrm{Mel}$ the binding energy) is added to the two low sst neutronenergy values (which come mostly from the $(n, \gamma)$ reactionl, and $7 \mathrm{McV}$ (the $n, 2 \mathrm{n}$ threshold energy) is subtracted from ihe 14.8-MeV value (which comes mostly from the $(n, 2 n)$ reaction), then the energy scale essentially correspunds in the axcitation energy in the residual nuclerus, ano all values of $\mathrm{R}\left(\mathrm{E}_{\mathrm{n}}\right.$ ) fall close to a linear behavior.

To obtain a functional relationsnip of the $R$ parameter on excitation energy, a reaction must be chosen in which the excitation energy is uriquely known, i. c., a reaction that is preduminant in the neutronenergy range oi inturest. Eor tungsten, the neutron-energy range $t \leq \mathrm{F}_{n} \leq 7.5 \mathrm{MeV}$ (four data posnts) was chosen. The excitation energy ata calculated as $U_{i}\left(E_{n}\right)$

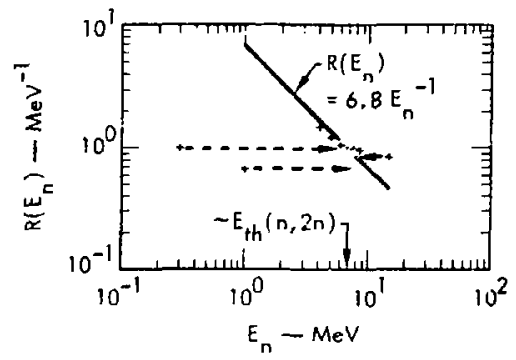

Fig. 4. $K\left(f_{n}\right)$ for tungsten obtained irom the cexper lenentias data. 89-9l crosecs denote. experimental points.
$=E_{n}-\bar{E}_{n}$, where $\bar{E}_{n}$, is the arerage energy of the inelastically scattered neutron and where $\mathrm{r}_{n^{\prime}}=2 \mathrm{~T}_{\mathrm{n}},=0.475 \mathrm{k} \mathrm{n}^{1 / 2}$. 'This procedurc gives two relations for the $\mathrm{R}$ parameter, both fitting the data equally well :

$$
\begin{aligned}
& \mathrm{R}_{\mathrm{i}}\left[\mathrm{U}_{\mathrm{i}}\left(\mathrm{E}_{n}\right)\right]=5.2 \mathrm{U}^{-1}, \\
& \mathrm{R}_{\mathrm{i}}\left[\mathrm{U}_{\mathrm{j}}\left(\mathrm{E}_{n}\right)\right]=2.5 \mathrm{U}^{-1 / 2} .
\end{aligned}
$$

The weighted $R$ parameter, $R\left(L_{n}\right)$, was then calculated as follows. For the average snergy of the two emergent neutrons from the $(n, 2 n)$ reaction, : 2 expression, $2 \overline{\mathrm{E}}_{2 \mathrm{n}}-4 \mathrm{~T}_{2 \mathrm{n}}=0.95\left(\mathrm{E}_{n}-, \mathrm{n}_{2 \mathrm{n}}\right)^{1 / 2}$ was used. Neutron-induced re...tion cross sections were tiken from the LLL Evaluated Nuclear Data Library (ENDL). It ivas further assumed for the continum gammas that,

- The $(n, \gamma)$ reaction is predominant for $\mathrm{E}_{\mathrm{n}}^{\prime}<2 \mathrm{MeV}$.

- The $\left(n, n^{\prime} \gamma\right)$ reaction is predominant for $4 \leq \mathrm{E}_{\mathrm{n}} \leq 7.5 \mathrm{MeV}$.

- No gammas occur from the $(n, 2 n)$ reaction for $\mathrm{E}_{t h_{21_{i}}} \leq \mathrm{E}_{\mathrm{n}} \leq 9.5 \mathrm{MeV}$. A simple hand calculation ${ }^{92}$ was then made, the re;ults of which are shown in Fig. 5. The igreement with experiment

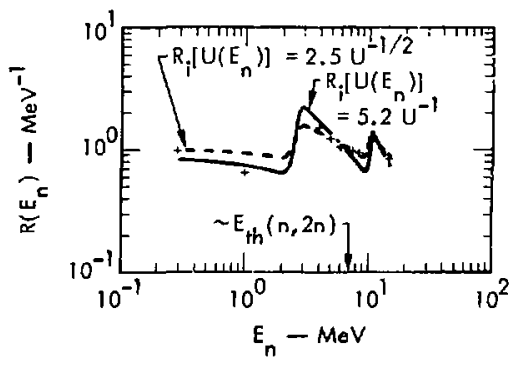

Fig. 5. $R\left(E_{n}\right)$ for tungsten: experiment (denoted by + ) vs calculation. 


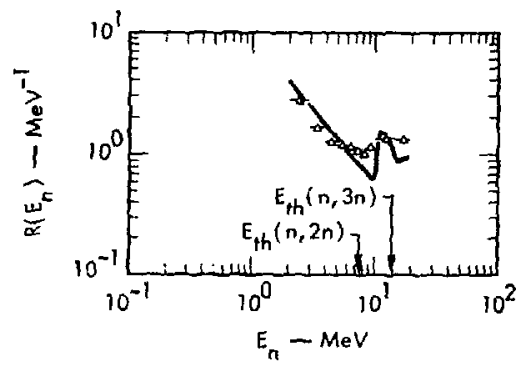

Fig. 6. $P\left(E_{n}\right)$ for ${ }^{18 J}$ Ta. The $-\Delta-$ denote experimental data, 42 and the curve denotes calculated ir sults, using $R=5,2 \mathrm{U}^{-1}$ irom tun', sten.

is relatively good, and the calculations clearly show the trend of $R\left(E_{n}\right)$ with incident neutron energy.

In developing the first set of $(n, x \gamma)$ cross sections and spectra for ${ }^{181} \mathrm{Ta}$, we extrapolated the tungsten results since no experimental data were then available for ${ }^{161} \mathrm{Ta}$. The functional bebavior for the $R$ parameter was taken as $\mathrm{R}_{i}\left[\mathrm{U}_{i}\left(\mathrm{E}_{n}\right)\right]$ $=5.2 \mathrm{~L}^{-1}$. Figure 6 compares the calculated results with subsequent experimental data. 42 The agreement, alihough probably fortuitous, is relatively good except just above thresholds, where the simple cal-culational technique was inadequate, With $R\left(E_{n}\right)$ known, the $(n, x \gamma)$ sross section was calculated by the Howerton and Plechaty formalism. 3

\section{MFCENT JEVELOPMENTS}

In 1972, Perey and coworkers at ORNL performed an $(n, x \gamma)$ experimc $n t$ on ${ }^{181} \mathrm{Ta}^{42}$ in one of the most comprehensive measurements carried out to date. Gamma-ray spectra $\{b / s \cdot$ MeV\} above

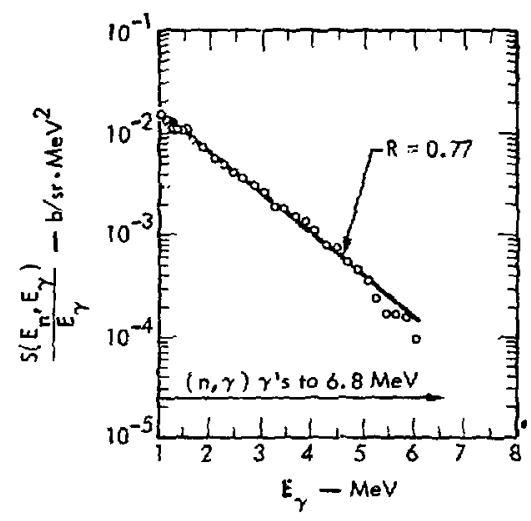

Fig. 7, ${ }^{181} \mathrm{Ta}(\mathrm{n}, \mathrm{x} \gamma)$ spectra for neutron energies $0.500 \leq \mathrm{E}_{\mathrm{n}} \leq 0.700 \mathrm{MeV}$. Data are for 125 uegrees. 42

1-MeV photon energy were measured at two angles and at incident r.eutron energles between 0.007 and $20 \mathrm{MeV}$. These spectra were analyzed for $\mathbf{R}$ parameters over the entire incident neutron-energy range. ${ }^{88}$ Some typical resulzs are show in Figs, ithrough 10. This analysis yielded the following observations.

- The evaporafion model adequately describes the spectrum over the entire incident neutron-energy range, even when the only component present is $\langle n, \gamma\rangle$.

- When both the $(n, \gamma)$ and the $(n, n[\gamma)$ reactions are present $\left(1 \leq \mathrm{E}_{n} \leq 4 \mathrm{MeV}\right)$, each appears to have its own evaporatinn spectrum, yielding two distinct $R$ parameters at each neutron energy. Thus, the $R$ parameter is reaction-dependent at a specific neutron energy.

These results allowed us for the first time to obtain $R_{i}$ ( $C$ ), using two reactions $\left[(n, \gamma)\right.$ and $\left.\left(n, n^{\prime} \gamma\right)\right]$ between the excitation energies $1 \leq U \leq 10 \mathrm{MeV}$. Figure 11 
shows the results of taking the averagc energy of the $(n, n$ ') neutrons from the inelastic continum-neutron spectra in the LLL ENDL. The figure also shows that when the excitation energy for the two reactions is the same, the $R_{i}(U)$ are equal, indicating essentially no dopendence on the specific rusiclual nucleus.

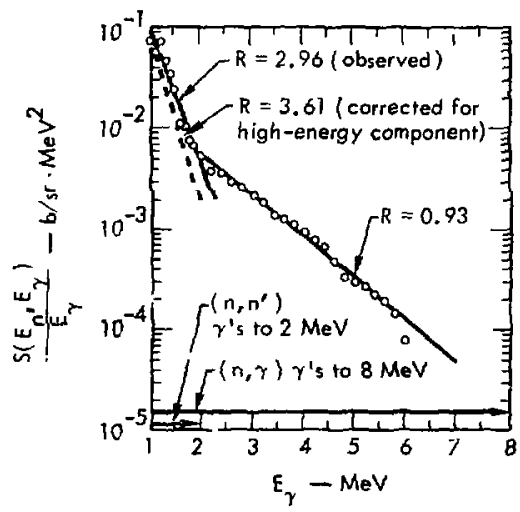

Fig. B, 18! Ta(n, $x \gamma)$ spectra for neutron energies $1 \leq \mathrm{E}_{n} \leq 2 \mathrm{MeV}$. Data are for 125 degrees. 42

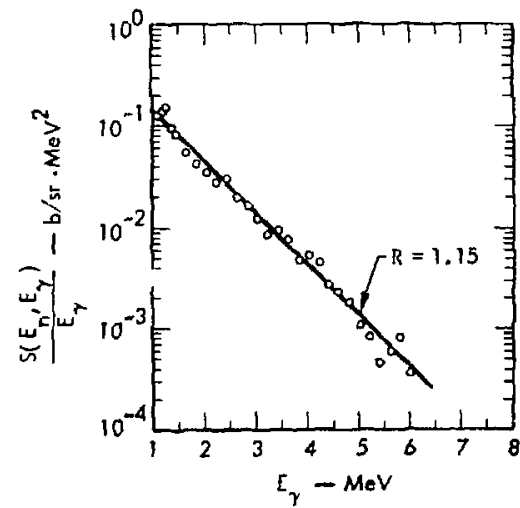

Hig. 9. 1817aln, xyi spectra for neutron energies $9.06 \leq \mathrm{F} \leq 9.13 \mathrm{MeV}$. Jata are for 125 degrees. 42
Furthermore, at high ixcitation energics, $R_{i}$ (U) appears to approach a constant value.

This new information allowed us to extend ${ }^{93}$ the ho verton and Plecbaty formalism, as follows:

- The gamma rays from each individual reaction are assumed to follow an evaporation spectrum, with the $\mathrm{R}$ parameter taken from the excitation-function dependence. Hence, $(n, x)$ ) cross sections can be calculated for each reaction by the Howerton and Plechaty formalism and then summed to obtain the total continuum $(n, x \gamma)$ cross section.

- The combined spectrum of photons is obtained by weighting the individual spectra by the appropriate cross section and then summing them.

We applied this extended formalism to $R_{i}(U)$ (Fig. 11) and to the reaction cross sections and average secondary neutron

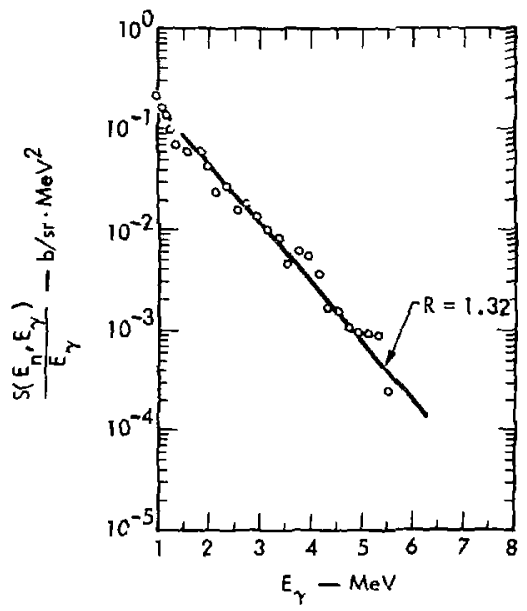

Fig. 10. $38{ }^{1} \mathrm{Ta}\left(n_{z} \times \gamma\right)$ spectra for neutron energies $15.08 \leq k_{n} \leq 19.97$ MeV. Jata are for $125 \mathrm{de}$ greis. 42 


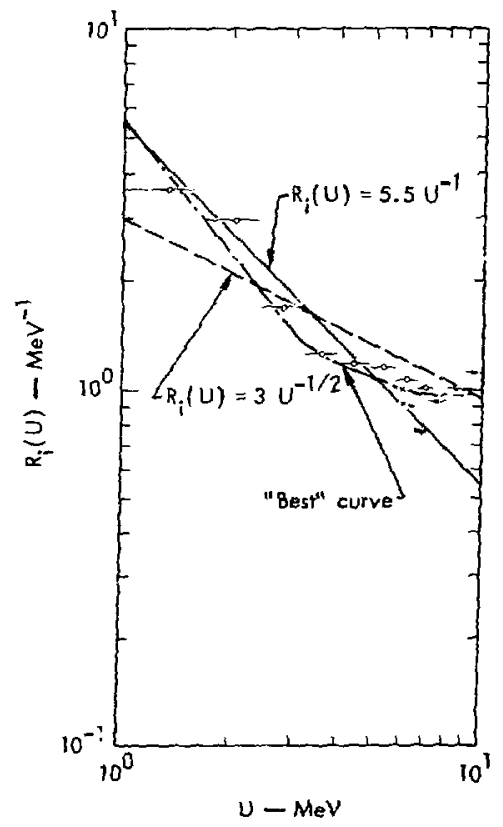

Fig. 11. $R_{\mathrm{i}}(\mathrm{U})$ for $181 \mathrm{Ta}$ as obtained from experimental results. 42 The -0 - denote pure $\left(n, n^{\prime}\right)$ and the $-x-$ denole pure $(n, \gamma)$. The uncertainty in $R_{i}(U)$ is at least $10 \%$.

energies (LLI ENDL). These calculations were 1 hen compared with Perey's ${ }^{181} \mathrm{Ta}$ experimental results. As the experiment only included photons above $1 \mathrm{MEV}$, just the continulum component of the $\left(n, n^{2}\right)$ cross section was used; if any reaction at a given neutron energy yjelded an excitation inergy less than $1 \mathrm{MeV}$, it was assumed to make no contribution to the $(n, x y)$ calculation.

The results of the comparison are shown in Fig. 12. For the $(n, x y)$ cross section, the agreement between calculation and eperiment is about $20 \%$ or better as

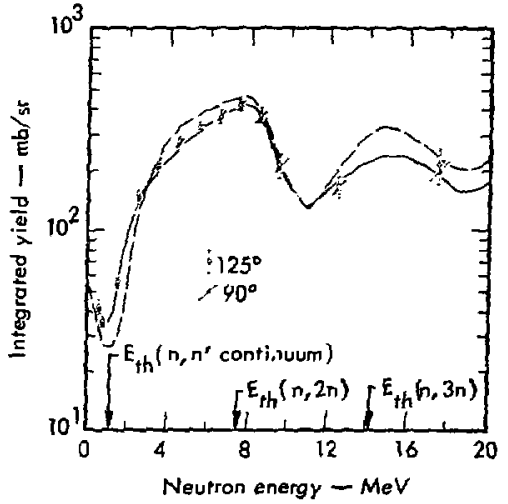

Fig. 12. $181 \mathrm{Ta}(n, \mathrm{x} \gamma)$ cross section above 1-MeV photon energy. Solid curve and points are experimental, 42 dastied curve is the calculation.

all anargies except $2 \mathrm{MeV}$, where the calculation is about $40 \%$ low. These calculations show that this technique of analysis is adequate for obtaining continuum $(n, x y)$ cross sectinns ano spectra.

\section{THE SFCOND-PASS $\{n, x \gamma\rangle$ EVALVATION}

In this section, we describe the technique for obtaining a final evaluated set of $(n, x y)$ cross sections over the neutron energy range $10^{-11} \leq \mathrm{E}_{n} \leq 20 \mathrm{MeV}$. The total gamma-ray prociuction is considered to be composed of discrete and continuum components, as shown in Table 2.

Table 2. Component and energy description $r$ f evaluated $(n, x \gamma)$ production for ${ }^{181} \mathrm{Ta}$.

\begin{tabular}{ll}
$\begin{array}{l}\text { (n, xy) } \\
\text { component }\end{array}$ & $\begin{array}{c}\text { Energy range } \\
\text { (MeV) }\end{array}$ \\
\hline Iotal & $10^{-11}$ to 0.035 \\
Discrete & 0.035 to 20 \\
Continuum & 0.035 to 20 \\
\hline
\end{tabular}


Total $\left(n, x_{i}\right)$ Production $\left(10^{-11} \leq \mathrm{E}_{\mathrm{n}}\right.$ $\overline{\$ 0.035 \mathrm{MeV})}$

The orly reaction that produces gamma rays in this energy region is $(n, \gamma)$. The discrete and continuum components of the spectrum at thermal energy have been measured. 94,95 They are combined with a calculated spectral shape as discussed below in the section on gammaray energy distributions. The resulting spectrum has an average energy $\overline{\mathrm{E}_{\gamma}}$ (thermal), At other neutron energies, $E_{\gamma}\left(E_{n}\right)$ can also be obtainer. If no internal conversion occur's, the multiplicity as a function of neutron energy $E_{n}$ is in general taken to be

$$
M\left(E_{n}\right)=\frac{\frac{181}{182} E_{n}+Q_{n, \gamma}}{\bar{E}_{\gamma}\left(E_{n}\right)}
$$

where $Q_{n, \gamma}$ is the $(n, \gamma) Q$-value. Corrections necessary to account for internal conversion are iadicated in the section on continuum transitions.

The accuracy of this procedure is cluarly dependent on how alcurate the spectral shape is. The uncertainty for gamma-ray production below $0.035 \mathrm{Mel}$ is estimated to be $20 \%$ over and above the uncertanty in the $(n, y)$ cross section.

$(n, x \gamma)$ Discrete Component $\left(0.035 \leq E_{n}\right.$ 20 M०VI

After inelastic ixcitation of ${ }^{181} \mathrm{Ta}$ for neut ron energies bet low $2.6 \mathrm{Mel}$, some J3 discrete lines have been reported. 29,33,34,96 Recent unpublished measurements of Dirkens and Morgan 27 with iraproved resolution show many more Iines and "xtend the neutron energies to 5 MeV. For our evaluation, 2: gamma rays are c onsidered significant. In rases where the transitions have been identified, the gamma production cross sections were renormalized to the inelastic-scattering data, especially thost of Ref. 24. The correspondence between inelastic neutron cross sections and gamma rays included corrections for internal conversion ${ }^{97}$ and considerations of the known gammaray branching ratios, 1,98

For some transitioas, notably those at $0.1361,0.1524,0.4822,0.3461,0.1935$, and $0.3589 \mathrm{MleV}$, the renormalization amounted to about a factor of 2. Other transitions required no renormalization. The explanation of this difference is not known. If this problem is ignored, the uncertainties in the production cross sections for each of the 22 lines is estir.:ated to be about $25 \%$.

An unmeasured transition at $0.0062 \mathrm{MeV}$ is expected between the first excited state and ground state of ${ }^{181} \mathrm{Ta}$. Thr production cross section for this transition was obtained from the $\left\{n, n^{\prime}\right\}$ cross section calculated with COMNUC by Gardner ${ }^{28}$ and from the measured ${ }^{27}$ cascades through the levels at 0.1586 and $0.3375 \mathrm{MeV}$. Because the transition goes by internal conversion $98^{\circ}, 0$ of the time, ${ }^{99,100}$ the production of $0.0062-\mathrm{MeV}$ photuns is considered to be negligible.

$K$ and $L x$ rays following internal conversion of the discrete lines and $K, L$, and $M x$ rays following internal conversion of continuum transitions are also included in the evaluation. The $\mathrm{K} \times$ rays following discrete transitions are assumed for simplicity to be $\mathrm{K}_{\alpha} \mathrm{x}$ rays, for which the a verago energy is taken to be $0.0574 \mathrm{Mel}$. The $L \times$ rays come from $L$ internal conversion and from $K$ conversion followed by a $\mathrm{K}_{a r} \mathrm{x}$ ray. In each case there is a 
vacancy in the L-shell, which is assumed to lead to the emission of a $0.010-\mathrm{MeV}$ photon. This assumption handles the total energy properly, but it neglects the complicated $x$-ray cascade involving photons less energetic than $0.010 \mathrm{MeV}$.

For continuum transitions, the $\mathrm{K} \times$ rays again was assumed to be a $K_{\alpha} \times$ ray $(E=0.058 \mathrm{MeV})$. The $L$ \& ray, however, was taken to be an $L_{a} \times$ ray $(E=0.0082$ MeV), which occurs when an L-shell vacancy is filled by an M-shell electron. The $\mathbf{M}$-shell vacancies were assumed to be filled by unbound electrons, giving an $M_{\infty} \times \operatorname{ray}(E=0.0017 \mathrm{MeV})$. The method of calculating the cross sections for these $x$ rays is described in the following section.

For all of the $x$ rays, fluorescent yields of $100 \%$ are assumed and Auger processes are ignored. The uncertainties in $\mathrm{K}, \mathrm{L}$ and $\mathrm{M} \mathrm{x}$-ray production cross sections are as large as those in the conversion-electron cross sections dis* cussed later.

$(n, x y)$ Continuum Component $(0.035$ $\mathrm{E}_{\mathrm{n}} \leq 20 \mathrm{MeVl}$

The calculation of continuum gammaray production cross section and spectra and of the associated $x$ rays has been described at length. ${ }^{101}$ we give here only a brief outline of the calculation and indicate the modifications to Ref. 101 necessary for this evaluation. The following definitions are required.

The differential energy-production crose section for the $y^{\text {th }}$ emergent particle, $\sigma_{n, x y}\left(E_{n}-E_{y}\right)$, is defined as $\sigma_{n, x y}\left(E_{n}-E_{y}\right)=\sigma_{n, x y}\left(E_{n}\right) \pi_{y}\left(E_{n} \rightarrow E_{y}\right)$.

where

$$
\begin{aligned}
& y=\left\{\begin{array}{l}
\gamma \text { for gamma rays } \\
\beta \text { for electrons } \\
\text { i for the } i^{\text {th }} \mathrm{x} \text {-ray line, }
\end{array}\right. \\
& E_{n}= \text { incident neutron kinetic } \\
& \text { energy in the lab system, } \\
& E_{y}= \text { emergent kinetic energy of } \\
& \text { particle y in the lab system, } \\
& \sigma_{n, x y}\left(E_{n}\right)= \text { integrated } y^{\text {th }} \text { production } \\
& \text { cross section, } \\
& \pi_{y}\left(E_{n} \rightarrow E_{y}\right)= \text { probability for emission of } \\
& \text { particle y normalized to } \\
& \text { unity. }
\end{aligned}
$$

Furthermore, the average excitation energy: $U\left(E_{n}\right)$, in the residual nucleus is equal to

$U\left(E_{n}\right)=E_{n}+Q_{0}-\overline{E_{r}\left(E_{n}\right)}-\overline{E_{n}^{\prime}\left(E_{n}\right)}$,

where

$\overline{E_{r}\left(E_{n}\right)}=$ average recoil kinetic energy of residual nucleus and charged particles in the lab system,

$\overline{E_{n}^{\prime}\left(E_{n}\right)}=$ ave rage kinetic energy of all emergent neutrons in the lab system,

$Q_{0}=$ reaction (binding energy difference) $Q$-value.

$U\left(E_{n}\right)$ may also be expressed specifically in terms of the average total available energy for particle $y, U_{y}\left(E_{n}\right)$, as

$$
U\left(E_{n}\right)=\sum_{y} U_{y}\left(E_{n}\right)
$$

The multiplicity or particle $y, M_{y}\left(E_{n}\right)$, is defined as the average number of emergent particles per reaction: that is,

$$
M_{y}\left(E_{n}\right)=\frac{\pi n_{, x y}\left(E_{n}\right)}{\sigma\left(E_{n}\right)}
$$

or equivalently,

$$
M_{y}\left(E_{n}\right)=\frac{U_{y}\left(E_{n}\right)}{E_{y}\left(E_{n}\right)} .
$$


The pertinent $x$-ray energies, $E_{i}$, are given by

$$
\begin{aligned}
& E_{K}=\overline{E_{B E}^{K}}-\overline{E_{B E}^{L}}, \\
& E_{L}=\overline{E_{B E}^{L}}-\overline{E_{B E}^{M}} .
\end{aligned}
$$

and

$$
E_{M}=\overline{E_{B E}^{M}} \text {. }
$$

The system of equations that was solved consists of three relationships. The first expresses that the excitation energy in the residual nucleus, after nucleon and other heavy-particle emission ceases, goes into gamma-rays, conversion electrons, and $\mathrm{x}$-rays:

$$
\begin{aligned}
U\left(E_{n}\right)=M_{\gamma}\left(E_{n}\right) & \overline{E_{\gamma}\left(E_{n}\right)}+M_{\beta}\left(E_{n}\right) \overline{E_{\beta}\left(E_{n}\right)} \\
& +\sum_{i=K, L, M} M_{i}\left(E_{n}\right) E_{i}
\end{aligned}
$$

The second relationship defines the ratio of conversion electrons to gamma rays:

$\frac{\sigma_{n_{2} \times \beta}^{\xi}\left(E_{n}-E_{\beta}^{\xi}\right)}{\sigma_{n, x}{ }^{\prime}\left(E_{n}\right)}=\alpha^{\xi}\left(E_{\gamma}\right) \pi_{\gamma}\left(E_{n} \rightarrow E_{\gamma}\right)$,

where $\alpha^{\xi}\left(E_{\gamma}\right)$ is the coefficient for internal conversian from the $\xi^{\text {th }}$ atomic shell.

These coefficients have been tabulated for various multipolarities. ${ }^{97}$ The kinetic energy of the electron, $E_{\beta}^{\xi}$, is equal to

$$
E_{\beta}^{\xi} \equiv E_{\beta}^{\xi}\left(E_{\gamma}\right)=E_{\gamma}-\overline{E_{B E}^{\xi}} .
$$

where $\overline{\mathrm{E}_{\mathrm{BE}}^{F}}$ (defined to be positi 'e) is the lowest electron binding energy in the $\xi^{\text {th }}$ shell.

The third set of relationships gives the $x$-ray multiplicities in terms of the conversion electron multiplicities.

$$
\begin{aligned}
& \frac{M_{K}\left(E_{n}\right)}{M_{\gamma}\left(E_{n}\right)}=\frac{M_{\beta}^{K}\left(E_{n}\right)}{M_{\gamma}\left(E_{n}\right)}, \\
& \frac{M_{L}\left(E_{n}\right)}{M_{\gamma}\left(E_{n}\right)}=\frac{M_{\beta}^{K}\left(E_{n}+M_{\beta}^{L}\left(E_{n}\right)\right.}{M_{\gamma}\left(E_{n}\right)} .
\end{aligned}
$$

and

$$
\frac{M_{M}\left(E_{n}\right)}{M_{\gamma}\left(E_{n}\right)}=\frac{M_{\beta}^{K}\left(E_{n}\right)+M_{\beta}^{L}\left(E_{n}\right)+M_{\beta}^{M}\left(E_{n}\right)}{M_{\gamma}\left(E_{n}\right)} .
$$

This system of equations was solved given $\mathrm{U}\left(\mathrm{E}_{\mathrm{n}}\right)$, the gamma-ray spectrum. and the mu'tipolarity of the continuum gamma rays. For the evaluation, $U\left(E_{n}\right)$ was taken from the neutron emission spectra and known Q-values. The continuum gamma-ray spectra are discussed in the next section. In the absence of data, the multipolarity of all continuum transitions was taken to be M1.

For the (n, n') reaction, Eq. (6) required a correction because a part of the excitation of ${ }^{181} \mathrm{Ta}$ is described in this evaluation as excitation of discrete states. We call this quantity $U_{n, n},\left(E_{n} \rightarrow\right.$ discrete levels). Furthermore, these levels decay by the emission of discrete gamma rays with total energy $\mathrm{E}_{\gamma \mathrm{d}}$, discrete conversion electrons with energy $E_{c}, e, d^{*}$ and associated $x$ rays with energy $E_{x,} d^{*}$ The following relationships then hold:

$$
\begin{aligned}
& U_{n n^{\prime}}\left(E_{n} \rightarrow \text { discrete }\right)=\sum_{j} E_{j} \sigma_{j}\left(E_{n}\right) / \sigma\left(E_{n}\right), \\
& E_{\gamma, d}=\sum_{l} E_{\gamma \ell} \sigma\left(E_{n} \rightarrow E_{\gamma, \ell}\right) / \sigma\left(E_{n}\right), \\
& E_{c,(\ldots, d}=\sum_{l} E_{c, t ., f} \sigma\left(E_{n} \rightarrow E_{c . e . . l} / \sigma\left(E_{n}\right),\right.
\end{aligned}
$$


and

$E_{i, d}=E_{i} \sigma\left(E_{n}-E_{i, d}\right) / \sigma\left(E_{n}\right)$,

where $E_{j}$ is the energy of the $j^{\text {th }}$ discrete level, $\sigma_{j}\left(E_{n}\right)$ is the crogs section for excitation of that level by $(n, n)$ inelastic scattering, $E_{y_{1}} f$ is the energy, and $\sigma\left(E_{n} \rightarrow E_{y, d}\right)$ is the cross section for production of the $f^{\text {th }}$ discrete emergent particle y. Then Eq, (6) becomes

$$
\begin{aligned}
U\left(E_{n}\right) & +U_{n, n^{+}}\left(E_{n}-\text { discrete }\right) \\
& =M_{\gamma}\left(E_{n}\right) \overline{E_{\gamma}\left(E_{n}\right)}+M_{\beta}\left(E_{n}\right) \overline{E_{\beta}\left(E_{n}\right)}
\end{aligned}
$$

$$
\begin{aligned}
+\sum_{i=K, L, M} M_{i}\left(E_{\pi}\right) E_{i} & +E_{\gamma, d}+E_{c, \epsilon, d} \\
& +\sum_{i=K, L, M} E_{i, d}(12)
\end{aligned}
$$

The terms that carry over from Eq. (6) now are defined just for continuum processes.

The evaluated $(n, x \gamma)$ cross sections are estimated to be accurate to about $\pm 25^{\circ} \%$ except near $2 \mathrm{MeV}$, where the errors can be as large as $\pm 50 \%$.

\section{Angular Distributions for Gamma-Ray and X-Ray Production}

The only experimental data on gammaray angular distributions in tantalum are the recent data of Perey and coworkers. ${ }^{42}$ These data indicate that gamma-ray pro- duction is essentia. y isotropic. Hence, isotropy was assumed for all gammaproducing reactions. The $\mathrm{x}$-ray angular distributions were also assumed to be isotropic.

\section{Energy Distributions for Gamma-Ray and X-Ray Productio.}

$(n, \gamma)$ REACTION $\left(10^{-10} \leq E_{n} \leq\right.$ $0.035 \mathrm{MeV}$ )

In the $(n, \gamma)$ reaction, the gamma-ray spectral shape has been measured at thermal neutron energies, ${ }^{94,95}$ The measurements of the spectral shape were comuined as tollows. For gamma-ray energies below $500 \mathrm{keV}$, the relative intensities of Ref. 95 were normalized at the 402-keV line to Ref. 94. K and L $x$ rays were added with intensities determined from conversion-electron yields (see below). For $\mathrm{E}_{\gamma}=500 \mathrm{keV}$ to $2.25 \mathrm{MeV}$, the gpectral shape was calculated ${ }^{28}$ Irom a gamma-ray cascade model. For $E_{\gamma}=2.25$ to $5 \mathrm{MeV}$, the data of Ref. 94 were used for the spectral shape. Above $5 \mathrm{MeV}$, the data of Ref. 95 were normalized to Ref, 94 and were used because of their superior resolution. The resulting spectrum is quoted in the form of a normalized probability distribution and binned for convenience.

At $E_{n}=2-k e V$, only the high-energy primary gamma rays have been measured. 95 They were combined with the spectrum below $E_{\gamma}=5 \mathrm{MeV}$ as discussed above. For $E_{n}=2$ - to $35-k e V$, the spectrum was assumeo to remain constant. Above $E_{n}=35 \mathrm{keV}$, all gamma rays from the $(n, \gamma)$ reaction are included in the continuum component discussed below. 
The mutiplicity of gamma rays as a function of neutron uncrgy, $M_{\gamma}\left(1 i_{n}\right)$, was determined from the equation of the preceeding section on continuum gammaray cross sections. This method of determining the multiplicity implies a disagreement with the assignments of Kef. 95 for gamma rays below $500 \mathrm{keV}$. li usc.d, these assignments would imply that in our evaluation the re at least twice too many transitions with $\mathrm{E}_{\gamma}<500 \mathrm{keV}$ to the ground and $16-\mathrm{ke} V$ states of ${ }^{182} \mathrm{Ta}$ per casturc. The cornbined uncertainty in the Jata used, howevir, is only about $30^{\circ} \%$. In any cait, a change in the spectrum of a factor of 2 belou $\mathrm{F}_{\gamma}-500 \mathrm{ke} v$ does not change $\bar{E}_{\gamma}$ or $M_{\gamma}\left(\mathrm{E}_{n}\right)$ very much. H. consider the uncertainties for $0.5 \leq \mathrm{r} \mathrm{z}_{\gamma} \leq 2.25 \mathrm{Me} \cdot \mathrm{V}$ to be about $30 v_{i}$ and for $F_{\gamma}>2.25$ to be $20^{s}$. In specific resonances, discrete gamma rays can be strongly enhanced, and hence the crrors can bi: much larger than those given h.re.

(n, xy) ISLSCRETE COMPONENT

$\{0.035 \leq \mathrm{E}: \leq 20 \mathrm{Mel}\}$

In the $\left(n, n^{+} \gamma\right)$ reaciiurt, 22 discrete gamma rays and $k$ and $L$ - $x$-ray art included in this evaluatiun. Discrete gamma rays $\operatorname{irom}(n, 2 n \gamma)$ and $(n, 3 n \gamma)$ have not been investigated experimentally and hence are not included in this evaluation.

$(n, x y)$ CONTINL UM COMPONENT $\left(0.035 \leq E_{n} \leq 20 \mathrm{Mel}\right)$

The manner in which continuum gamma rays wer. handled is best discussed in the framewo:k of Figs. l through 3 . In Fig. 1, the (n, n'y) reaction in the $\mathbb{E}_{n}^{L}$ region wat always assumed to occur. Thus, the $n^{1}$ aeutron had an average energy given by 'he evaporation spectrum appropriate to the excitation cnergy $\mathrm{L}_{\mathrm{A}}$ for that bombarding encrgy $\mathrm{F}_{n}$ (using the iteration procedure described on page 6 ). The $\left(n, n^{\prime} \gamma\right)$ reaction in the $F_{n}^{H}$ region required special handling (see pp. 6 and 7 ) but again an average neutron cucrgy $E_{n}^{\prime}$ corresponding to the incident energy $E_{n}$ was determined. Thus, for a given incident energy, $E_{n}$, a total rinal-state energy (denoted as $\mathrm{L}_{A}$ in Fig. 1) was available for the gamma rays, conversion electrons, and $x$ rays. Similarly, for the $(n, 2 n)$ and $(n, 3 n)$ reactions (Figs. 2 and 3 ), average neutron energies $E_{n l}$, $E_{n_{2}}$ and $E_{n_{3}}$ were determined, and a single final-state total energy $\mathrm{U}_{\gamma}$ appears for each incident energy $E_{n}$ and for each reaction.

In calculating the gamma-ray energy spectrum for ea'h bombarding energy $E_{n}$, the value of the average excitation energy $U\left(E_{n}\right)$ of the residual nucleus $w$ as first determined from the nevtronics file. Then the "best" $R(U)$ value (see p. 13) was used to calculate a gamma-ray spectrum that had a maximum gamma ray energy, $U_{\max }\left(E_{n}\right)$, and a shape given by:

$$
\begin{array}{r}
\pi_{\gamma}\left(E_{n} \rightarrow E_{\gamma}\right)=A\left(E_{n}\right) E_{\gamma} \exp \left(-B \cdot\left[L\left(E_{n}\right)\right] E_{\gamma}\right) \\
\text { for } E_{\gamma_{\min }} \leq E_{\gamma} \leq U\left(E_{n}\right), \quad \text { (13) }
\end{array}
$$

arid

$$
\begin{aligned}
& { }_{\gamma}\left(E_{n} \rightarrow E_{\gamma}\right)=A\left(E_{n}\right) E_{\gamma} \exp \left\{-R\left(U\left(E_{n}\right)\right] E_{\gamma}\right\}
\end{aligned}
$$

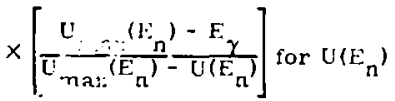

$$
\begin{aligned}
& \leq E_{\gamma} U_{\max }\left(E_{n}\right) \text {. }
\end{aligned}
$$

As with neutron spectra, the photon spectra have varying degrees of uncertainty, depending upon the emergent 
photon energy. The overall ecror in the spectrum is estimated to be about $30 \%$, with much larger errors at high and low photon energies.

\section{Cross Sections for Conversion-Electron Production}

The internal conversion process competes with gamma emission in the decay of exciteci states. The production cross sections and spectra of the conrersion electrons (c, e.) are evaluated here for discrete and continum transitions. We have considered only $\mathrm{K}$ and $\mathrm{L}$ conversion electrons for the discrete transitions with one exception, which is discussed below. The $L_{J}, L_{L I}$ and $L_{1 I I}$ conversion electrons have been lumped logether. $K$ and $\mathcal{L} x$ rays following internal conversior have been included with the gamma rays and are necessary to conserve energy. For continuum transitions, $K, L$, and $M$ internal conversions are included from a calculation. The various $M$ subshells are lumped together.

$(n, \gamma)$ REACTION $\left(10^{-10} \leq E_{n} S\right.$
$0.035 \mathrm{MEV})$

At thermal neutron energy, the conversion-electron spectrum has been measured from the ${ }^{181} \mathrm{Ta}(\mathrm{n}, r)^{182} \mathrm{Tu}$ reaction. 102,103 The multiplicity was determined from this spectrum and from Eqs. (2). (5), (6), and (7) using a value of $a$ determined from the reported c.e./ $\gamma$ intensity ratio. 102 This normalization therefore involves the same problem discussed for low-energy gamma rays in the reaction: namely, the asslgnments of Ref. 85 are inconsistent with our normalization and would say it should be reduced by a factor of two or more. The combined uncertainty in the data quoted is only about $30 \%$, however.

The multiplicity was recalculated at $E_{n}=35 \mathrm{keV}$ and kept constant from there to $20 \mathrm{MeV}$. Because the spectrum at thermal is dominated by only a few lines, large errors are possible at other neutron energies if the relative intensities of these few lines change.

$(n, x c, e$,$) DISCRETE COMPONENT$ $\left(0.035 \leq \mathrm{E}_{\mathrm{n}} \leq 20 \mathrm{MeV}\right)$

The $0.0062-\mathrm{MeV}$ state in ${ }^{181} \mathrm{Ta}$ is populated in the (n, n') reaction. It decays by $M$ and $N$ converted transitions 103 about $97.8 \%$ of the time. 99,100 For $E_{n}$ $\leq 0.137 \mathrm{MeV}$, it can be populated only by the $(n, n)$ reaction; above this energy it can be populated by $\left(n, n^{\prime}\right)$ reactions to higher-lying states, which then decay to the 6-keV state [i. e., an $\left[\mathrm{n}, n^{\prime} \gamma\right)$ reaction]. The cross section below $\hat{E}_{n}=0.137 \mathrm{MeV}$ for conversion electrons is therefore

$$
\begin{aligned}
& \sigma(c . \text { e. })=0.978 \cdot \sigma\left[n_{*} n^{\prime}(Q=-6 \mathrm{keV})\right] \\
& \times 6 \mathrm{kev} / \overline{\mathrm{E}}_{\mathrm{c}, \mathrm{e} .}
\end{aligned}
$$

where $\overline{\mathrm{E}}_{\mathrm{c} . \mathrm{E}}$ is the average energy of the conversion electrons.

For $E_{n}=0.137$ to $7.7 \mathrm{MeV}$, the data of Dickens and Morgan 27 for Gamma-ray production (normalized where secessary 
as stated above) were combined with branching ratios, ${ }^{1,98}$ interpolated conversion coefficients, ${ }^{97}$ and known $104-106$ or assumed multipolarities for the gamma rays given in Table 3 .

The other transitions of Refs, 27 and 33 are negligibly small sources of conversion electrons. For $E_{n}=7.7$ to $20 \mathrm{MeV}$, the cross sections were estimated.

(n, xc. e.) CONTIN JUM COMPONENT $\left(0.035 \leq E_{n} \leq 20 \mathrm{MeV}\right)$

The continuum component of the cross section for conversion-electron production was obtained for $0.035 \leq E_{n} \leq 20 \mathrm{MeV}$ through the foinalism 101 summarized above. An M1 muitipolarity was assumed for all continuum transitions.
Table 3. Kuow : or assumed muitipolarities for spenified gamma rays.

\begin{tabular}{ll}
\hline $\begin{array}{c}E_{\gamma} \\
(\mathrm{MeV})\end{array}$ & Multipolarity \\
\hline 0.1361 & $\mathrm{M1}$ \\
0.1378 & $\mathrm{E2}$ \\
0.1524 & $\mathrm{M} 1$ \\
0.1654 & $\mathrm{M1}$ \\
0.1789 & $\mathrm{M} 1$ \\
0.1935 & $\mathrm{M1}$ \\
0.225 & $\mathrm{M} 1$ \\
0.259 & $\mathrm{M} 1$ \\
0.288 & $\mathrm{M} 1$ \\
0.301 & $\mathrm{E2}$ \\
0.331 & $\mathrm{E2}$ \\
0.345 & $\mathrm{E2}$ \\
0.3589 & $\mathrm{E2}$ \\
0.482 & $\mathrm{E2}$ \\
\hline
\end{tabular}

\section{Angular Distributions for Conversion-Electron Production}

Isotropy is assumed for all reactions.

This is consistent with the same assumptio made for gamma-ray production.

\section{Energy Distributions for Conversion-Electron Production}

These spectra are given as normalized probability distributions.

(n, r REACTION: $\left(10^{-10} \leq \mathrm{E}_{n}\right.$ $\leq 0.035 \mathrm{MeV}$ )

The measurements of Kefs, 102 and 103 were combined and binned. Where only the $L$ conversion line was reported, a $K$ canversion line was added with an intensity appropriate to the multipolarity. The very low-encrgy $(<25 \mathrm{keV})$ electrons were estimated and could be significantly in error. This spectrum, while meas- ured only at the rmal, was assumed to obtain at all nelutron energies. (n, xc, e.) DISCRETE COMPONENT
$\left(0,006 \leq E_{n} \leq 20 \mathrm{MeV}\right)$

The spectra wert deduced from the evaluated gamma-ray data. The intensities of $l i$ and $\mathbf{L}$ conversion electrons were based on the ger.ma-ray yields and standard conversion coefficients 97 for the multipolarities indicated above. The $K$ conversion-electron energies are $E_{K}=E_{\gamma}-0.0674 \mathrm{MeV}$, and the $\mathbf{L}$ 
conversion-electron energies are $E_{L}$ $=E_{\gamma} \quad 0.010$ MeV. La addition, the complicated spectrum of conversion electrons from the deexcitation of the D. n623-MeV level ${ }^{100}$ was treated for simplicity as a line at $3.1 \mathrm{keV}$. This evergy, half the transition energy, was chosen to represent the $\mathrm{M}$ and $\mathrm{N}$ conversion electrons as well as the Auger cascade electrons and the very low-energy atomic photons. which guickly become photoelecrons. (n, xc. e.) CONTINULM COMPONENT

$\left(0.035 \leq \mathrm{E}_{n} \leq 20 \mathrm{Me} \mathrm{I}^{\prime}\right)$

The continuum spectra of conveision electrons were derived from the calculated $(n, x \gamma)$ continuum spectra described above according to E'q. (7). A multipolarity of $M 1$ was assumed for all er tinuum transitions.

Because the spectra and multipolarity of continuum gamma rays had to be assumed, there may be large errors in the cross sections and spectra for continuum conversion-electron production.

\section{An Integral Test of the Evaluated Data}

Very recently Bogart and coworkers 107 measured the emission spectrum from a relatively thick ( $3.4 \mathrm{mfp}$ at $4 \mathrm{MeV}$ ) spherical shell of tantalum. The source was

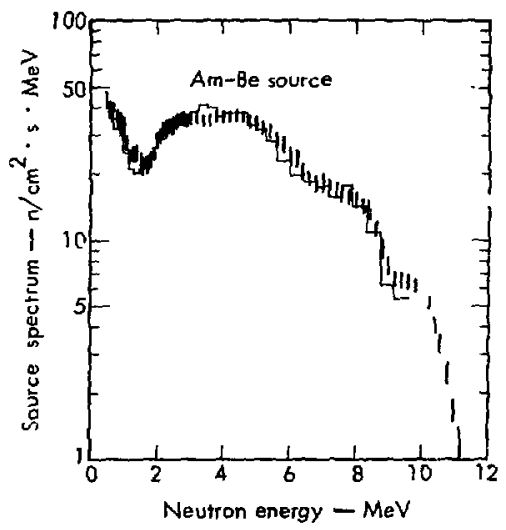

Fig. 13. Neutron-leakage spectrum for the $241_{A m-B e}$ sour ce sphere. The histogram is the calculation using the June $197 \notin$ version of ENDL. Error bars are the experimental points.
241 Am-Be int mately mixed and formed into a 5.4 -cm-diam sphere.

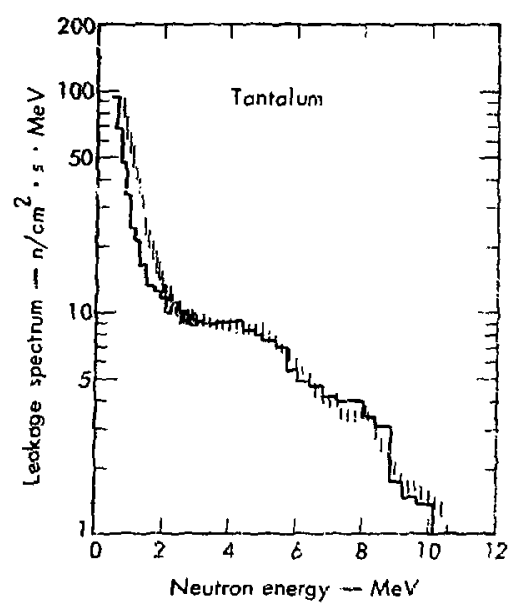

Fig. 14. Neutron-lukage spectrum frcm the small. tantalum spherical sheli surrounding the $241 \mathrm{Am}-\mathrm{Be}$ source sphert. The histogram is tho calculation with the present evaluaticn. Frror bars are tine exprrimental points. 
The spectrum from this extended source was calculated using the so-called "virgin source" (Po-Be) described in Ref. 107. The Monte Carlo code TART was used with evaluated data $10 \%$ for $B e$ and for 242 Arn, since ${ }^{241}$ Am evaluated data were not available. |The number of ${ }^{342} \mathrm{Am}\{\mathrm{n}, \mathrm{f}\}$ zyents in this calculation and in that for the tantalum shell were each less than $0.4 \%$ of the source neutrons. Thus the substitution for ${ }^{241} \mathrm{Am}$ by ${ }^{2+2} \mathrm{Am}$, which has a $m^{*}=h$ higher fission cross section a. therrual, makes little difference here.] The calculation was normalized to the measured source spectrum and is shown with the experimental data in Fig. 13.
The emission spectrum from the source surrounded by the spherical shell of tantalum was then calculated $w$ ith the source strength as normalized by the calculation of the bare ${ }^{241} \mathrm{Am}-\mathrm{Be}$ source. The residits are compared with experiment in Fig. 14. Very good agreement is found for neitron e'ries above $2 \mathrm{MeV}$. The disagreement below $2 \mathrm{MeV}$ could be due either to inaccuracies in the experiment near the detector threshold or to inaccurate $\left(n, n^{\prime}\right)$ emission spectra in the evaluation. More data are required on the emission spectra to resolve this problem.

\section{Acknowledgments}

The authors would like to thank the Defense Nuclear Agency for partially supporting this work under Subtask W99QAXPC102. The authors are especially grateful to Drs. J. K. Dickens and G. L. Morgan for providing their unpublished $\{n, x y\rangle$ data, to Dr. 5 . T. Larsen for providing unpublished gamma-ray branching ratios, and Dr. D. G. Gardner for performing the COInNuC calculations. R. C. Haight wishes te thank Dr. Dickens for his hospitality during the week when the $(n, x \gamma)$ daia were analyzed. 


\section{References}

1. Y,A. Ellis, Nucl, Hata, Sect, B g, 319 (1973).

2. R. J. Howerton, Thresholds of Nuclear Reactions Induced by Neutrons, Photons, Douterons, Tritors, and Alpha Particies, Lawrence Livermore Laboratory, Rept. LCRL-50400, vol, 9 (1970).

3. V. V. Vladimirskii, I. A. Radkewich, ard W. W. Sokolowsky, "Cross Sections Important to Keactor Design," in Proc. Inter. Conf, Peaceful Lses : tomic En: ergy (United Nations, New York, 3955) vol. 4, p. 22.

4. P. A Vigelstaff, Iaw rence Livermore Laboratory, private communication (1956).

5. C. K. Bockelman, K. E. Peterson, R, K. Adair, anó H. H. Barschall, Phys. Kev. 76, 277 (1949).

6. K. K. Seth, Lawrence Livermore Jaboratory, private communication, (1965): see also K. It Tabony and $K$. K. Seth, Ann. Phys. 46, 401 (1968).

7. A. B. Smith, P. T. Guenther, R. Hayes, and J. F. Whalen, Fast-Neutron Scattering From TanLalum, Rherium, and Platinum, Argonne National Laboratory, 111** Rept, ANL-7363 (1967).

8. N.G. Nereson and S. Darden, Survey of Average Neutron Total Cross Sectians Irom 3 to $13 \mathrm{MeV}$, Los Alamos Scientific Laboratory. N. Mex.s Rept. LA-J655 (1954); see also Phys. Rev. 89, 775 (1953) and Phys, Rev, 94, 1678 (1954).

y. M. Halk and J. R. Beyster, Phys. Rev, 98,677 (1955).

10. A, D, Carson and H. H. Harschall, Phys. Rev, 158, 1142 (196i).

11. i. H. Coon, E. R. Graves, and H. H. Barschall, Phys. Rey, 89, 502 (1953),

12. J. P. Conner, Phys. Rev. 109, 1268 (1958).

13. H. W. Newsin, J. H. Gibbons, H. Marshak, R. M. Williamson, R. C. Nobley, J. R. Pattersom, and P. F. Nichols, Phys. Rev, 105, 198 (1957).

14. E. Melkonian, If. W, Aavens, Jr., and L. J. Rainwates, Phys, Rev. 92. 702 (1953).

15. R. C. Martin, P. F. Yergin, R, H. Auguston, N. N. Kaushal, H, A, Medicus, and E. J. Wintold, Bull. Am. Phys, Soc, 12, 106 (1967).

16. D. W. Miller, R. K. Adair, C. K. Bockelman, and S. E. Darden, Phys. Rev. 8g, 03 (1952).

17. D. G. Foster, Jr, and D. W, Glasgow, Lawrence Livermore Laboratory, prisate communication (1967).

18. 1. Bratenatul, J. M. Peterson, and J. P. Stoering, Neutron Total Cross Sections in the 7 - to $14-$ MeV Region, Lawrence Livermore Laboratory, Rept. LCRL-4980 (1957); see also Phys, Rev, 110, 927 (1958).

19. J. M. Peterson, A. Bratenahl, and J. P. Stoering, Phys, Rev. 120, 521 (1960).

20. M. Walt and H. H. Barschall, Phys. Rev, ?: 1062 (1954).

21 J. K, Heyster, M. Walt, and K. W. Salmi, Phys. Rev. 104, 1319 (1956). 
22. L. Rosen and L. Stewart, Phys, Kev. 107,824 (1957).

23. L. Ya. Kasakova, V. E. Kolesov, V. I. Popov, G. A. Salnikov, Y. M. Sluchevskaja, and $V$. I. Trikova, in Proc, Lnter. Conf. Study Nucl, Structure with Neutrons (Ainsterdam, North Holland, 1966).

24. A. B. Smith, P. T. Guenther, and J. F. Whalen, Phys. Rev. 168, 1344 (1968). See also: A. B. Smith and P. T. Guenther, Trans. Am. Nucl. Soc. 7, 267 (1964); A, B. Smith, C. A Englebrecht, and D. Reitmann, Reactor Physics Division Annual Report, July 1, 1963 - June 30, 1964, Argonne National Laboratory, 111.. Rept. ANL-7010 (1969); J. P. Chien and A. B. Smith, Nucl. Sci. Eng. 26, 500 (1966); D. Lister, A. B. Smith, and C. Dunford, Fast Neutron Scattering from the 182,184 , and 86 1sotopes of Tungiten, Argonne National Laboratory, Ill., Rept. ANL-7288 (1967); A. B. Smith and R. Hayes, Nucl. Phys. 93, 609 (1967).

25. Reactor Development Program Monthiy Progress Report, Argonne National Laboratory, Lll., Rept. ANL-6485 (1961).

26. W. L. Rogers, D. I. Garbes, and E. F. Shrader, Bull. Am. Phys. Soc. 6, 61 (1961).

2r. J. K. Dickens and G. L. Morgen, Oak Ridge National Laboratorv, Tenn., private cc. ...nunication (1973).

2b. D. G. Gardner, Law rence Livermore Laboratosy, private communication (1973).

29. J. B. Guernsey and A. Wattenberg, Phys, Rev, I01, 1516 (1956).

30. D. B. Thomson, Phys, Rev, 129, 1649 (1963).

31. I. Rosen and L. Stewart, Phys. Rev. 10?, 224 (195.,.

32. N. P. Glazkov, At, Energ, 15, 416 (1963).

33. V. C. Rogers, I. E. Beghian, and F. M. Clikeman, Nucl. Sci. Eng. 45, 297 (1971); see also Trans, Am. Nucl. Soc, 12, 746 (1969) and Nucl. Phys, Al44, 81 (1970).

34. D. L. Broder, A. F. Gamalii, A. I. Lasuk, B. V. Nesterov, and I. P. Sadokhin, Fiziko-Energeticheskii institut, Obninsk, Rept. FEl-155; also reported in Proc. Inter. Conf, Nucl. Data Reactors, 2nd Helsink: 1970 (IAEA, Vienna, 1970), CONF-700605, vol. 2, p. 295.

35. V. I. Ashby, H, C. Catron, L. L. Newkirk, and C. J. Taylor, Absolute Measurement of $(n, 2 n)$ Cross Sections at $14.2 \mathrm{MeV}$, Lawrence Livermore Laboratory, Kept. UCRL-5054 (1953); see also Phys. Rey. 111, 616 (1958).

36. E. B. Paul and R. L. Clarke, Can. J. Phys. 31, 269 (1953).

37. M. Hormann, A, Behrendt, and $O$. Vogel, in regogress Report on Nucl. Data Research in the Euratom Community, January 1-December 31, 1967, p. 59 .

38. J. Bry?ko, B, Fryszczyn, E. Gierlik, A. Saganek, A, Soltan, Jr., and 2. Wilhelmi, Excitation Curve of the Reaction $181_{\mathrm{Ta}}\left(\mathrm{n}_{2} \mathrm{2n}\right) 180 \mathrm{~m} \mathrm{Ta}$, lnstitute of Nuclear Research, Warsaw, Rept. 1NR-795/1/PL (1967).

39. A. Poularikas, J. Cunningham, W. McMillan, J. McMillan, and R, W. Fink, J. Inorg Nucl. Chem, 13, 196 (1960). 
40. B. P. Bayhurst and R. J. Prestwood, $(n, 2 n),(n, p)$ and $(n, \alpha)$ Excitation Functions of Several Nuclei from 7.0 to $19.8 \mathrm{MeV}$, Los Alamos Scientific Laboratory. N. Mex., Rept. LA-2493 (1960); see also Phys, Rev. 121, 1438 (1961) and I. $_{2}$ Innrg. Nucl. Chem. 23, 173 (1961).

41. H. K. Vonach, W. G. Vonach, H. Munzer, and P. Schramel, "Precision Measurements of Excitation Functions of $(n, p),(n, \alpha)$, and $(n, 2 n)$ Feactions Induced by 13.5- tn 14.7-MeV Neutrons," in 2nd Conf, Neutron Cross Sections and Technology (National Eureau of Standards, Washington, D. C., 1968), p. 885.

42. G. L. Morgan, I. A. Love, J. K. Dickens, and F. G, Perey, Gamma-RayProduction Cross Sections of Tantalum and Carbon for Incident Neutron Energies between 0.007 and $20,0 \mathrm{MeV}$, Oak Ridge National Laboratory, Tenn,. Rept. ORNL-TM-3702 (1972).

43. R. J. Howerton and E. F. Plechaty, Nucl. Sci, Eng. 32, 178 (1968).

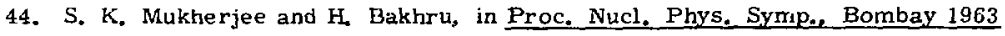
(India Dept. of Atomic Energy, Bombay, 1963), p. 244.

45. J. S. Brzosko, E. Gierlik, A. Soltan, Jr., and Z. Wilhelmi, Nucl. Phys, A123, 603 (1969).

46. M. C, Moxon and E, R. Rae, Nucl. Instrum. Methods 24, 445 (1963).

47. See the 1963 data of Ref. 43 .

48. A. D. Carlson, Gulf General Atomics, private communication (1970); see also M. P. Fricke, M. M. Lopez, S. J. Friesenhahn, A, D. Carlson, and D. G. Costello in Pr:.. Inter. Conf. Nucl. Data for Reactors, 2nd, Helsinki, 1970.

49. H. O. Menlove and W. P. Ponitz, Nucl. Sci. Eng. 33, 24 (1968); see also "Some New Measurements and Renormalizations of Neutron Capture Cross Section Data in the keV Energy Range, "in Proc. Symp. Fast Reactor Physics and Relatid Safety Problems, Karlruhe, Germany, 1967, p. 67.

50. R. L. Macklin and J. H. Gibbons, Bull. Am. Phys. Soc. 11, 167 (1966).

51. R. L. Macklin, J. H. Gibbons, and T. Inada, Nurl. Phys, 43,353 (1963).

52. R. L. Macklin, J. EL Gibbons, and T. Inada, Phys. Rev, 129, 2695 (1963).

53. V. N. Kononov and Yu. Ya. Stavisskii, At. Energ. 19, 457 (1965i.

54. V. N. Konov, Yu. Ya. Stavisskii, V. E. Kolesov, A. G. Dovbenko, V. S. Nesterenko, and V. I. Moroka, Yad. Fiz. 4, 282 (1966).

55. 1. Bergqvist, Arkiv Fysik 23, 425 (1962).

56. A, 1. Leipunsky, O. D. Kazachkovgky, G. Y. Artyukov, A. I. Baryshnikov, T. S. Belanova, V. I. Galkov, Yu. Ya. Stavisskii, E. A. Stumbur, and L. E. Sherman, "Measurements of Radiative Capture Cross Sections for Fast Neutrons," in Proc, I. N. Inter. Conf, Peaceful Uses of Atomic Energy, 2nd (United Nations, Geneva, 1958), vol. 15, p. 50; see also V. N. Kononov, Yu. Ya. Stavisskii, and V. A, Tolstikov, At. Energ. 5, $564(1958)$ for 21-keV cross sections, both activation and gamma-gamma coincidence measurements. 
57. H. Arino, H. H. Kramer, v. J. Molínski, R. S. Tilbury, W. H. Wahl, and P. M. Stier, Research in Activation Analysis, Union Carbide Corp., Rept. NYO- 10175 (1964).

58. V. A. Konks, Yu, P. Popov, and F. L. Shapiro, J. Exp. Theor, Dhys. 46, 80 (1964).

50. R. C. Block, G. G. Slaughter, L. W. Weston, and F. C. Vonderlage, Physics Division Annual Progress Report, Oak Ridge National Laboratory, Tenn,, Rept. ORNL-3085 (1961), p. 48 .

60. J. H. Gibbons, R. L. Macklin, P. D. Miller, and J. H. Neiler, Phys, Rev. 122, 182 (1961); see also Bull. Am. Phys. Soc. 4, 385 (1959).

61. J. A Miskel, K. V. Marsh, M. Iindner, and R. J. Nagle, Neutron-Activation Cross Sections, Lawrence Livermore Laboratory, Rept, UCRL-6690 (1961); see also Phys. Rev, 128, 2717 (1962).

62. S. A, Cox, Phys, Rev, 133, 378 (1964).

63. B. C. Diven, J. Terrell, and A. Hemmendinger, Phys, Rev, 120, 556 (1960).

64. Reports to Atomic Energy Commission Nuclear Cross Section Advisory Group, U. S. Atomic Energy Commission, Rept. WASH-192 (1956).

65. R. Booth, W. P. Ball, and M. H. MacGregor, Neutron Activation Cross Sections at $25 \mathrm{keV}$ Lawrence Livermore Laboratory, Rept. UCRL-5005 (1957): see also Phys. Rev, 112,226 (1958).

66. L. Seren, H. N. Friedlander, and S. H. Turkel, Phys, Rev, 22, 888 (1947).

67. G. Wolf, Nukleonik 2,255 (1960).

68. A, W. Sunyar and P. Axel, Phys. Rev, 121, 1158 (1961).

69. W. S. Lyon, Nucl. Sci. Eng, B, 37B (1960).

70. R. P. Schuman and J. R. Berreth, Resonance Integral Measurements, ldaho Nuclear Corp., ldaho Falls, Rept. IN-1296 (1960). See also Rept. IN-1126 (1967), p. 19. Reports to the Atomic Energy Commission Nuclear Crosis Seclions Advisory Committee, U.S. Atomic Energy Commission, Repts. WASH1136 (1969), p. 53-54 and WASH-1124 (1968), P. 72.

71. R. Sher, Stanford University, Stanford, California, private communication (1966).

72. A. Langsdorf, Jr., R. O. Lane, and J. E. Monahan, Neutron Scattering Angular Distribution, Argonne National Laboratory, Ill., Rept. ANL-5567 (1956); see also Repts. ANL-5554 (1956), p. 22; ANL-5567 (1961 Rev.); Phys. Rev. 107, 1077 (1537).

73. A. B. Smith, Argonne National Laboratory, Argonne, 11l, private communıcation (1962), data received from NNCSC.

74. S. E. Darden, R. B. Perkins, and R, B, Walton, Phys, Rev, 100, 1315 (1955): gee also M. D. Goldberg, V. M. May, and J. R. Stehn, Angular Distrioutions in Niutron-Induced Heactions, Brookhaven National Laboratory, Upton, N. Y., Ku.pt. $13 N L-400$ (1962).

7.) W. B. Gilboy and J. H. Toxle, Nucl, Phys. 42, 86 (1963). 
76. S. E. Darden, W. Hatberli, and R. B. Walton, Phys, Rev. 96, 836 (1954). Data read from BNL-400.

77. R. L. Becker, W. G. Guidon, and G. J. Smith, Nucl. Phys, 89, 154 (1966).

78. A. E. Remund, Helv. Phys, Acta 29, 545 (1956).

79. S. G. Buccino, C. E. Hollandsworth, and P. R. Bevington, Z. Physik 196, 103 (1966).

80. A. Yoshimura, M. Sonoda, A. Katase, Y. Wakuta, M. Seki, T. Akiyoshi, 1. Fujita, and M. Hyakutake, Kyushu $L$. Yodern Dannym., private communication (1965), data via Brookhaven National Laboratory Sigma Center; see also Byull. Inform. Tsentra (1965), p. 24 for a orief discussion.

81. J. O. Elliot, Phys, Rev, 101, 684 (1956).

82. W. G. Cross and R. G. Jarvis, Nucl. Phys. 15, 155 (1960).

83. K. Tsukada, Japan, private communication (1962).

84. J. M. B. Lang and K. J. LeCouteur, Proc, Phys, Soc. (London) A67, 586 (1954).

85. S. Pearlstein and E. J. Winhold, J, Nucl. Energy, Parts A/B 19, 497 (1965).

86. O. A. Sal'nikov, N. I. Fetisov, G. N. Lovchikova, G. V. Kotel'nikova, V. B. Anufrienko, and B. V. Devkin, Sov, J. Nucl. Phys, 4, 1154 (1966),

87. H. Sobottka, S. Grimes, P. Huber, E. Mangold, J. Schacher, and R. Wagner, Helv. Phys. Acta 43,559 (1970).

88. S. T. Perkins, "A Tabulation of Experimental R Parameters for Use in the Howerton and Plechaty Recipe" (unpublished).

89. J. L. Perkin, Nucl. Phys, 60, 561 (1964).

90. U. $\because$ Tucker, Texas Nuclear, Austin, Rept. ORO-2791-32 (1971).

91. D. M. Drake, J. C. Hopkins, C. S. Young, and H. Conde, Nucl. Sci, Eng. 40, 294 (1970).

92. S. T. Perkins, "A Simple Hand Calculation of the (n, Xy) Spectra and Cross Section Based on the Howerton and Plechaty Recipe" (unpublished).

93. i. T. Perkins, "NXGAM, A Code to Calculate Continuum ( $\left.n_{4} \times y\right)$ Cross Sections and Spectra" (unpublished).

94. V. J. Orphan, N. C. Rasmussen, and T. L. Harper, "Line and Continuum Yields from Thermal Neutron Capture in 75 Elements, "Gulf General Atomic, San Diego, Rept. GA-10248 (1970), also listed as Rept. DASA-2570.

95. R. G. Heimer, R. C. Greenwood, and C. H. Reich, Nucl. Phys. Al68, 449 (1971).

96. R. B. Jay, Phys, Hev, 102, 767 (1956).

97. R. $\therefore$ Hager and E. C. Seltzer, Nucl. Data A4, 1 (1968).

98. J. T. Larken, Lawrence Livermore Laboratory, private communication (1973).

99. A, H. Muır, Nucl, Phys, 68, 305 (1968).

100. A. H. Muir and F. Boehm, Phys, Rev, 122, 1564 (1961). 
101. S. T. Perkias, R. C. Haight, and R. J. Howerton, A Technique for Calculation of Continuum Photon and Conversion Electron Production Cross Sections and Spectra from Neutron-Induced Raactions, Lawrence Livermore Laboratory, Rept. UCRL-757\$0 Rev. 1 (1974), accepted for publication in Nucl. Sci. Eng.

102. D. F. A. Goudsmit, Ph. D. thesis, Amsterdam University. The Netherlands, (1969), NTIS 18536.

103. Ya. K. Alksnis, M. K. Balodis, and P. T. Prokof'ev, Bull, Acad, Sci. USSR, Phys. Ser. 32, 1833 (1968).

104. H. Blumberg, R. S. Hager, and E. C. Seltzer, Nucl. Phys, Al3C, 624 (1969).

105. P. Alcxander, H, Ryde, and E. Seltzer, Nucl, Phys, 26,167 (1966).

106. F. T. Avignone 1Il, J. H. Trueblood, and Z. W. Grabowski, Nucl. Phys. A167, 129 (19? 1).

107. D. Bogart, D. F. Shook, and D. Fieno, Nucl. Sci. Eng, 53, 285 (1974).

108. R. J. Howerton, R. J. Doyas, T. C. Michels, and S. T. Perkins, An Integrated System for Production of Neutronics and Photonics Calculational Cons tants, Volume 4, Evaluated Nuclear Cross Section Library, Lawrence Livermore Laboratory, Rept, UCRL-50400 (1971).

JKP:bl'Ime 